The predictive power of dividend yields for future infl ation: Money illusion or rational causes?

\author{
Tom Engsted and Thomas Q. Pedersen
}

CREATES Research Paper 2016-11 


\title{
The predictive power of dividend yields for future inflation: Money illusion or rational causes?*
}

\author{
Tom Engsted and Thomas Q. Pedersen ${ }^{\dagger}$
}

April 2016

\begin{abstract}
In long-term US data the stock market dividend yield is a strong predictor of longhorizon inflation with a negative slope coefficient. This finding is puzzling in light of the traditional Modigliani-Cohn money illusion hypothesis according to which the dividend yield varies positively with expected inflation. To rationalize the finding we develop a consumption-based model with recursive preferences and money illusion. The model with reasonable values of risk aversion and intertemporal elasticity of substitution, and either rational or adaptive expectations, implies significantly negative slope coefficients that increase numerically with the horizon in regressions of future inflation onto the dividend yield, in accordance with the data. A purely rational version of the model with no money illusion, but with a link from expected inflation to real consumption growth, also generates a negative inflation-dividend yield relationship.
\end{abstract}

JEL Classification: C22, E31, E44, G12, G17

Keywords: Modigliani-Cohn money illusion, predictive regressions, long-run risk, Campbell-Vuolteenaho methodology

${ }^{*}$ Part of this research was done while Tom Engsted was visiting UC Berkeley and The Federal Reserve Bank of San Francisco in the fall of 2015. The help and hospitality of the people at those places are gratefully acknowledged. A special thanks to Michael Jansson and Kevin Lansing. The paper has benefitted from comments from participants at a seminar at the research department of the San Francisco Fed. The authors also acknowledge support from The Danish Council of Independent Research (DFF 4003-00022) and CREATES - Center for Research in Econometric Analysis of Time Series (DNRF78), funded by the Danish National Research Foundation.

${ }^{\dagger}$ Affiliation for both authors: CREATES, Department of Economics and Business Economics, Aarhus University, Fuglesangs alle 4, DK-8210 Aarhus V, Denmark. E-mail: tengsted@econ.au.dk (Engsted); tqpedersen@econ.au.dk (Pedersen). 


\section{Introduction}

The possibility that economic agents suffer from irrationality in the form of 'money illusion' has intrigued economists for more than a century. Since the book-length discussion of the phenomenon by Fisher (1928), the effects of money illusion has pervaded much of economic modeling. People who suffer from money illusion confuse nominal with real values. For example, they mistakenly consider an increase in the nominal value due to a generel increase in the price level to be an increase in the real purchasing power. Thus, they ignore inflation in processing information and in making decisions.

Following the 'IT-bubble' period of the 1990s, several papers have analyzed the effects of money illusion on stock valuations, e.g. Asness (2000, 2003), Sharpe (2002) and Ritter and Warr (2002). Some of these studies explicitly make the analysis within the framework of the socalled 'Fed model', which has been much used by practitioners to value stocks vs. bonds, and which relates the dividend yield, i.e. the dividend-price ratio, or earnings yield (a 'real' variable) to the nominal bond yield. It is generally recognized that the 'Fed model' does not provide a rational explanation for stock valuations. The apparent empirical success of this model thus indicates a significant degree of irrationality and money illusion in the stock market.

Campbell and Vuolteenaho (2004a,b) present a general framework for analyzing money illusion in the stock market ${ }^{1}$, and with various modifications their framework has been applied in several recent studies of money illusion in stock and housing markets, e.g. Brunnermeier and Julliard (2008), Chen, Lung, and Wang (2009), Lee (2010), and Acker and Duck (2013a,b). An essential part in Campbell and Vuolteenaho's methodology is a vector-autoregression (VAR) containing stock returns and additional state variables. The VAR model is used to infer 'objective' (rational) and 'subjective' (irrational) expectations of stock returns and dividend growth (housing returns and rent growth in the housing market applications), and to obtain a 'mispricing' measure that should be correlated with inflation if investors suffer from money illusion.

The empirical applications of this methodology in general show a significant mispricing component that is positively correlated with a proxy for expected inflation. Within the framework this positive correlation implies that the dividend-price ratio (rent-price ratio) is positively correlated with inflation such that in times of high (low) inflation stock (house) prices are 'too low' ('too high') relative to 'rational' valuations. Under rational

\footnotetext{
${ }^{1}$ Campbell and Vuolteenaho (2004a,b) use the term 'inflation illusion' instead of 'money illusion', but the two terms refer to the same phenomenon.
} 
expectations and no money illusion, valuation ratios like the dividend-price ratio should be unrelated to inflation. Campbell and Vuolteenaho (2004a,b) and the subsequent studies cited above interpret the positive correlation between the mispricing component (and thus the dividend-price ratio) and inflation as evidence in support of the type of money illusion suggested by Modigliani and Cohn (1979). Modigliani and Cohn conjecture that stock market investors, in contrast to bond market investors, suffer from money illusion so that they discount real cash flows with nominal discount rates. Thus, in times of high inflation the bond market correctly sets a high nominal interest rate but the stock market fails to adjust nominal cash flow expectations. At the time of writing (end of the 1970s) Modigliani and Cohn's hypothesis provided an explanation for the depressed stock prices at the time. Similarly, the hypothesis potentially explains the stock market boom of the 1980s and 1990s as a result of investors failing to account for the declining inflation over that period. Brunnermeier and Julliard (2008) interpret the housing boom of the 1990s and 2000s as a consequence of house buyers failing to understand the effects of declining inflation, in accordance with the Modigliani and Cohn hypothesis. The Campbell-Vuolteenaho methodology is purely empirical and not based on a specific economic model. However, Basak and Yan (2010) present an equilibrium asset pricing model based on money illusion that can explain the positive relation between the dividend-price ratio and expected inflation.

In the present paper we approach the money illusion hypothesis from a different angle. Motivated by the analysis in Engsted and Pedersen (2010) we investigate the predictive power of dividend yields for future inflation based on a simple rewriting of the Campbell and Shiller (1988a) log-linear present value relation. This relation relates the log dividend-price ratio to expected future returns and dividend growth. The relation holds for both nominal and real returns and dividend growth, and under rational expectations and no money illusion it implies that a change in expected inflation should - ceteris paribus - have no effect on the dividend-price ratio. By contrast, under money illusion the dividend-price ratio will move with expected inflation. In a regression of actual future inflation on the current dividend-price ratio, the slope coefficient should be 0 under no money illusion and different from 0 under money illusion. A further implication of money illusion is that the dividend-price ratio should predict nominal and real returns (and dividend growth) differently. These implications can be investigated using simple multi-period predictive regressions well-known from the finance literature (e.g. Campbell and Shiller (1988a,b), Fama and French (1988), Cochrane (2008)). ${ }^{2}$

\footnotetext{
${ }^{2}$ In an analysis similar in spirit to ours, Schmeling and Schrimpf (2011) also use a rewriting of the Campbell and Shiller (1988a) relation to investigate money illusion in the stock market. However, their
} 
We present empirical results on long-term US data showing that the dividend-price ratio is a very strong predictor of future long-horizon inflation. Regressing long-horizon inflation on the dividend-price ratio gives a negative and highly significant slope coefficient with $R^{2}$ values up to $34 \%$. In addition, the relationship is quite stable across different sub-samples and remains robust when controlling for the effects of time-varying risk-premia. Figure 1 shows the inverse of the dividend-price ratio (i.e. the price-dividend ratio) and subsequent 20-year inflation in the US over the period 1871-2012 (note that the final 20-year inflation observation is the rate of inflation from 1992 to 2012). The relationship is clearly visible. An implication of this kind of inflation predictability is that real stock returns are more predictable by the dividend-price ratio than nominal stock returns. This implication is confirmed in the data. In fact, while real long-horizon stock returns are significantly predictable, nominal long-horizon stock returns are not predictable.

Next, we develop an economic model with the aim of explaining the negative relation between dividend yields and future inflation. Building on the long-run risk setup of Bansal and Yaron (2004), our model features Epstein and Zin (1989) and Weil (1989) recursive preferences and a small persistent component in consumption and dividend growth. We extend this setup with a specification for inflation also containing a small persistent component. In addition, we follow Basak and Yan (2010) and specify the stochastic discount factor such that it accommodates money illusion, covering the whole spectrum from no money illusion to full money illusion. Basak and Yan's model employs constant relative risk-aversion (CRRA) preferences and iid consumption and dividend growth. Our model, by contrast, has recursive preferences and non-iid consumption and dividend growth. These differences turn out to be crucial for generating the negative relation between dividend yields and future inflation that we see in the data. Basak and Yan's model cannot generate such a negative relation.

Several versions of our model generate a negative relation between dividend yields and future inflation. In particular, the model with money illusion and reasonable values of the degree of relative risk aversion and intertemporal elasticity of substitution, and with either rational or adaptive expectations, implies significantly negative slope coefficients that increase numerically with the horizon in regressions of inflation onto the dividend yield, in accordance with the data. An alternative version of the model with no money illusion, but with a positive relation between consumption growth and expected inflation

focus lies in the use of short-term survey based measures of inflation, and they test for money illusion by regressing real stock returns onto lagged values of expected inflation. 
(following Burkhardt and Hasseltoft, 2012) also generates a negative slope coefficient in the inflation-dividend yield regression.

Thus, our analysis and results are consistent with money illusion in the stock market, although not necessarily the kind of money illusion suggested by Modigliani and Cohn (1979) and Campbell and Vuolteenaho (2004a,b). Campbell and Vuolteenaho find a positive relation between the dividend yield and a smoothed backward-looking non-rational measure of expected inflation. We find a negative relation between the dividend yield and actual future inflation, and this negative relation is consistent with an economic model featuring money illusion both under rational and adaptive (non-rational) expectations. When doing the Campbell-Vuolteenaho analysis on our data using a smoothed backward looking measure of expected inflation, we are able to confirm qualitatively Campbell and Vuolteenaho's results for their sample period. However, the results are not robust to changes in the sample period and to other changes in the modeling setup. In particular, when using the long-term nominal interest rate as a forward looking proxy for expected inflation, the analysis gives a negative relation between Campbell and Vuolteenaho's mispricing measure and expected inflation, in accordance with our direct inflation predictability regressions.

The rest of the paper is organized as follows. Section 2 presents the results from regressing multi-year inflation, nominal returns, and real returns onto the dividend-price ratio. In section 3 we develop an economic model to explain the inflation predictability results and present simulation results from the model that we compare with the actual data. In section 4 we investigate the Campbell-Vuolteenaho methodology and apply it on our data. Section 5 concludes. The Appendix contains a description of the bootstrap procedure to compute p-values in the predictability regressions, and it gives the detailed derivations of the central equations of the economic model.

\section{Predictive regressions}

\subsection{The log-linear present value relation}

The starting point for our analysis is Campbell and Shiller's (1988a) log-linear present value relation for the log dividend-price ratio (the dynamic Gordon growth model) 


$$
d_{t}-p_{t}=E_{t} \sum_{j=0}^{\infty} \rho^{j}\left(r_{t+1+j}-\Delta d_{t+1+j}\right)-\frac{c}{1-\rho}
$$

where $d_{t}$ and $p_{t}$ are $\log$ dividends and log stock prices, respectively, and $r_{t}$ is log return. $\rho=1 /\left(1+e^{E(d-p)}\right)$, and $c$ is a linearization constant. $E_{t}$ and $\Delta$ are the conditional expectations operator, conditional on information at time $t$, and the first-difference operator, respectively. ${ }^{3}$

Equation (1) holds for both nominal and real variables. If we define $r_{t+1+j}$ and $\Delta d_{t+1+j}$ in nominal terms and let $\pi_{t+1+j}$ denote log inflation from time $t+j$ to $t+1+j$, then we can write equation (1) as

$$
d_{t}-p_{t}=E_{t} \sum_{j=0}^{\infty} \rho^{j}\left[\left(r_{t+1+j}-\pi_{t+1+j}\right)-\left(\Delta d_{t+1+j}-\pi_{t+1+j}\right)\right]-\frac{c}{1-\rho}
$$

Thus, the dividend-price ratio reflects expected future returns and/or dividend growth either in nominal or in real terms. This just reflects the fact that the dividend-price ratio is independent of whether $d_{t}$ and $p_{t}$ are measured in nominal or real terms. The rewrited Campbell-Shiller relation, equation (2), is a dynamic accounting identity that automatically links the current dividend-price ratio to future long-term returns, dividend growth, and inflation. If expectations are fully rational so changes in expected inflation are correctly incorporated into both expected nominal returns and expected nominal dividend growth (the socalled 'Fisher effect'), then according to (2) a change in expected inflation will not change the dividend-price ratio (unless changes in expected inflation affect expected returns or dividend growth through some economic mechanism other than through the Fisher effect, cf. the discussion in section 2.2). However, if changes in expected inflation are not correctly incorporated into either expected nominal returns or expected nominal dividend growth (or both), then in general a change in expected inflation will lead to a change in the dividend-price ratio. To the extent that actual future inflation is positively correlated with expected inflation, the current dividend-price ratio will then be statistically related to actual future inflation.

Thus, under no money illusion a change in expected inflation does not change the dividend-price ratio. Econometrically, $d_{t}-p_{t}$ should have no predictive power for $\sum_{j=0}^{\infty} \pi_{t+1+j}$

\footnotetext{
${ }^{3}$ Equation (1) is derived based on a first-order Taylor expansion of the definition of the one-period return. Thus, there is a linearization error that makes (1) only hold approximately. Engsted, Pedersen, and Tanggaard (2012a) show, however, that the approximation error is negligible.
} 
in a regression of long-horizon inflation onto the dividend-price ratio. However, if $d_{t}-p_{t}$ in fact does have predictive power in such a regression, it indicates either the presence of money illusion or that expected inflation affects expected returns or dividend growth. Furthermore, such predictability implies that $d_{t}-p_{t}$ will predict nominal and real returns (and dividend growth) differently. As seen from (2), depending on the sign of inflation predictability, real returns (and/or dividend growth) will be either more or less predictable than nominal returns (and/or dividend growth). ${ }^{4}$

\subsection{Empirical results}

Table 1 presents regressions of inflation, nominal returns, and real returns, respectively, onto the dividend-price ratio:

$$
\begin{aligned}
\pi_{t, t+k} & =\alpha_{\pi, k}+\beta_{\pi, k}\left(d_{t}-p_{t}\right)+\varepsilon_{\pi, t+k} . \\
r_{t, t+k} & =\alpha_{n, k}+\beta_{n, k}\left(d_{t}-p_{t}\right)+\varepsilon_{n, t+k}, \\
\left(r_{t, t+k}-\pi_{t, t+k}\right) & =\alpha_{r, k}+\beta_{r, k}\left(d_{t}-p_{t}\right)+\varepsilon_{r, t+k} .
\end{aligned}
$$

$\pi_{t, t+k}=\sum_{j=0}^{k-1} \pi_{t+1+j}$ and $r_{t, t+k}=\sum_{j=0}^{k-1} r_{t+1+j}$ denote the sum of one-period log inflation and nominal log returns, respectively, from period $t$ to $t+k$. For $k=1$ we compute $t$-statistics using Newey and West (1987) hetereoskedasticity and autocorrelation robust standard errors, while for $k>1$ we use Hodrick (1992) standard errors, which for these types of regressions have better size properties in small samples than those by Newey and West (1987), cf. Ang and Bekaert (2007). As emphasized by Cochrane (2008, section 5.1) $k$ needs to be at least 15 to 20 years to get the power gains of long-horizon regressions, so we let $k$ take the values $1,5,10,15$, and 20 years. To account for potential smallsample bias that can arise due to the use of a highly persistent predictor variable such as the dividend-price ratio, we also report bootstrapped p-values computed under the null hypothesis of no predictability (see Appendix 1 for details of the bootstrap procedure). We use Robert Shiller's annual US data set, which covers the period 1871-2012. For the regressions in Table 1 we use S\&P stock prices and dividends as well as the Consumer Price Index to compute nominal and real stock returns, inflation, and the dividend-price ratio.

\footnotetext{
${ }^{4}$ According to (2) it should be future long-horizon discounted inflation, returns, and dividend growth (where the discount factor is $\rho$ ) that are related to $d_{t}-p_{t}$. Since $\rho$ is only slightly less than one, in practice it makes no difference whether the variables are discounted or not. In section 2.2 below we do not discount with $\rho$. We have done all regressions also using discounted values and none of the results change qualitatively.
} 
According to the results in Table 1 the dividend-price ratio predicts future inflation with a negative sign. For long horizons this predictability is highly significant as seen from the p-values roughly equal to zero for $k=15$ and 20. For $k=5$ and 10 we also find evidence of predictability using a $10 \%$ and $5 \%$ significance level, respectively. Only for $k=1$ we cannot reject that $\beta_{\pi, k}=0$. Evaluating the $R^{2}$ 's we see that the dividend-price ratio explains more than $34 \%$ of the following 20 -year inflation.

Figure 1 gives a visual picture of the degree of inflation predictability. The figure shows as the solid line the log price-dividend ratio (i.e. minus the log dividend-price ratio) and the subsequent 20-year log inflation rate (the dashed line). Inflation stops at 1992, the last year with a 20-year future inflation rate (from 1992 to 2012). There is a clear tendency that the two lines move together. It is particularly interesting to observe that during the 1970s, where the 'depressed' stock market at the time is often conjectured to coincide with high expected inflation, the fall in the price-dividend ratio coincides with falling subsequent 20-year inflation. On the other hand, the last few years in the graph may indicate a structural shift: from the beginning of the 1980s, the pricedividend ratio and subsequent long-term inflation are negatively related. That period marks the beginning of the long bull market in the US with the price-dividend ratio reaching an all-time high in year 2000 followed by a drop. This period is widely believed to be driven by a speculative bubble (e.g. Shiller, 2000). A bubble may have disturbed the relationship between the dividend-price ratio and future inflation during the 1980s and 1990s. However, the very low level of inflation the US economy has experienced in recent years coincides with the declining price-dividend ratio since year 2000, so a natural conjecture is that after 2000 the dividend yield is negatively related to long-term expected inflation.

To further evalute the robustness of our findings over time, Figure 2 shows $\widehat{\beta}_{\pi, k}$, the corresponding $t$-statistic, and the $R^{2}$ for $k=20$ obtained using both a forward and backward expanding sample sequence. In both cases the smallest sample size is 50 observations. In the forward expanding case the first sample is 1891-1940 (we begin in 1891 due to $k=20$ ) and then we recursively let the sample end point increase by one. In the backward expanding case the first sample is 1963-2012 and then we recursively let the sample starting point decrease by one. Correspondingly, in Figure 2 using the forward expanding sample sequence the horizontal axis gives the sample end point (with the sample always beginning in 1891), while using the backward expanding sample sequence the horizontal axis gives the sample starting point (with the sample always ending in 2012). Evaluating the results we see that the strong negative relation between the dividend-price 
ratio and long-horizon inflation is not restricted to the full sample period. The slope coefficient, $\widehat{\beta}_{\pi, k}$, remains negative for all sub-samples, the numerical $t$-statistic never drops below 3.0, and the $R^{2}$ generally remains high and only falls to $15 \%$ in the $1960 \mathrm{~s}$ and $70 \mathrm{~s}$. Thus, the results based on direct regressions of inflation on the lagged dividend-price ratio are robust across sub-samples.

The high degree of inflation predictability by the dividend-price ratio has important implications for the conclusions regarding stock return (and dividend growth) predictability by the dividend-price ratio. Evaluating return predictability in Table 1, we see that although the slope coefficient has the theoretically correct positive sign, cf. (1), irrespective of the horizon nominal returns are statistically unpredictable by the dividend-price ratio even using a 10\% significance level. The dividend-price ratio is, however, a strong predictor of future real returns. Taking small-sample bias into account we find evidence of real return predictability for $k=5$ and 10 using a $10 \%$ significance level and for $k=15$ and 20 using a $5 \%$ significance level in which case the $R^{2}$ is also around $30 \%$. With no money illusion, the dividend-price ratio should not predict inflation and, hence, should predict nominal and real returns similarly. The interesting implication of our findings is that if returns are truly unpredictable, negative inflation predictability (induced by e.g. money illusion) will make real returns predictable, as evidenced by the significant $\widehat{\beta}_{r, k}$ values in Table 1 . Conversely, if returns are truly predictable, such inflation predictability may make nominal returns unpredictable, as evidenced by the insignificant $\widehat{\beta}_{n, k}$ values in Table 1. We believe that these differences between nominal and real predictability in the US data are not generally acknowledged, although emphasized by Engsted and Pedersen (2010). ${ }^{5}$ Whether to interpret the empirical results as evidence of predictability or unpredictability of returns by the dividend-price ratio naturally hinges on the underlying economic model.

Before presenting an economic model with money illusion that can explain our empirical findings, we end this section by noting that a rational time-varying risk-premium that is directly affected by inflation may in principle explain that a lower (higher) dividend yield predicts higher (lower) future inflation: Assume that higher expected inflation decreases the risk-premium and, hence, decreases expected nominal stock returns. Then there will be two opposing effects at work. In the identity: 'Nominal stock return' = 'Nominal risk-free rate' + 'Risk-premium', an increase (decrease) in expected inflation

\footnotetext{
${ }^{5}$ The mirror image of return (un)predictability is dividend growth (un)predictability, cf. Cochrane (2008). Unpredictable nominal returns implies that nominal dividend growth must be predictable. This implication is confirmed in our data. By contrast, real dividend growth is not predictable by the dividend-price ratio. (Details are available upon request).
} 
will increase (decrease) 'Nominal risk-free rate' and decrease (increase) 'Risk-premium', whereby 'Nominal stock return' may stay constant or at least change less than the change in expected inflation. In terms of equation (2), when $E_{t} \pi_{t+1+j}$ goes up, $E_{t} \Delta d_{t+1+j}$ goes up by the same amount but $E_{t} r_{t+1+j}$ does not. Thus, $d_{t}-p_{t}$ decreases.

The above mechanism notwithstanding, if expected inflation has an effect on the dividend-price ratio through an effect on the risk-premium, it will be important to control for this in the inflation predictability regressions. To address this concern Table 2 shows regressions similar to those in Table 1 but where we now in addition to the dividend-price ratio use variables capturing the risk-premium as explanatory variables. We consider the following two regression models

$$
\begin{aligned}
& \pi_{t, t+k}=\alpha_{\pi, k}+\beta_{\pi, k}\left(d_{t}-p_{t}\right)+\beta_{\sigma, k}\left(\sigma_{s, t} / \sigma_{b, t}\right)+\varepsilon_{\pi, t+k} \\
& \pi_{t, t+k}=\alpha_{\pi, k}+\beta_{\pi, k}\left(d_{t}-p_{t}\right)+\beta_{m, k}\left(R_{m, t}-R_{f, t}\right)+\beta_{s, k} S M B_{t}+\beta_{h, k} H M L_{t}+\varepsilon_{\pi, t+k}
\end{aligned}
$$

where the first directly follows from the risk-premium proxy used by Campbell and Vuolteenaho $(2004 \mathrm{a}, \mathrm{b}) . \quad \sigma_{s, t} / \sigma_{b, t}$ is the relative volatility of stocks vs. that of bonds where volatility is computed using a rolling window of 10 years implying that the first available observation is in 1881 (see section 4.2 for a precise definition). In the second model we follow Brunnermeier and Julliard (2008, p.153) and use the Fama and French (1993) factors as a proxy for the risk-premium (FF3). The Fama-French factors are available from 1927 on Ken French's website, so for completeness we estimate the first model using both the full sample (1881-2012) and the sub-sample dictated by the availability of the Fama-French factors (1927-2012).

Irrespective of the proxy used, Table 2 shows that the strong negative relation between the dividend-price ratio and future long-horizon inflation remains even after controlling for the risk-premium. In general we cannot reject the null hypothesis $\beta_{\sigma, k}=0$ (except in 1927-2012 for $k=1$ ), while the Fama-French factors all appear highly significant for $k>1$.

\section{The economic model}

To evaluate potential explanations for the negative relation between the dividend-price ratio and future inflation, we derive an economic model that allows $i$ ) investors to suffer from money illusion and $i i$ ) real consumption growth to be related to expected inflation. 
The model is related to the long-run risk model of Bansal and Yaron (2004) based on Epstein and Zin (1989) and Weil (1989) recursive preferences. Our model is also related to the asset pricing model of Basak and Yan (2010) who consider the impact of money illusion but do so using time-separable power utility. We consider two scenarios regarding investors' expectation formation scheme. Investors can either have rational or adaptive expectations. Both analytically and through a simulation study, the model delivers important economic insights into possible explanations for the negative relation between the dividend-price ratio and future inflation.

\subsection{Investor preferences}

Common to all the scenarios we consider the representative agent is assumed to have Epstein and Zin (1989) and Weil (1989) recursive preferences,

$$
U_{t}=\left\{(1-\delta) C_{t}^{\frac{1-\gamma}{\theta}}+\delta\left(E_{t}\left[U_{t+1}^{1-\gamma}\right]\right)^{\frac{1}{\theta}}\right\}^{\frac{\theta}{1-\gamma}}, \quad \theta=\frac{1-\gamma}{1-\frac{1}{\psi}}
$$

where $C_{t}$ is real consumption at time $t, 0<\delta<1$ is the time discount factor, $\gamma \geq 0$ is the coefficient of relative risk aversion, and $\psi \geq 0$ is the intertemporal elasticity of substitution. In the special case where $\gamma=1 / \psi$, that is $\theta=1$, the above recursive preferences collapse to standard time-separable power utility. Note also that the sign of $\theta$ is determined by $\gamma$ and $\psi$. For example, $\theta$ will be negative if $\gamma>1$ and $\psi>1$, but positive if $\gamma>1$ and $\psi<1$. While there is general agreement that $\gamma>1$ the value of $\psi$ is subject to controversy. Hall (1988) and Beeler and Campbell (2012), among others, find evidence of $\psi<1$ while, for example, Attanasio and Weber (1993), Attanasio and Vissing-Jorgensen (2003), and Chen, Favilukas, and Ludvigson (2013) find $\psi$ to be above one.

Maximizing the utility function subject to the budget constraint $W_{t+1}=\left(W_{t}-C_{t}\right) R_{c, t+1}$ yields the following Euler equation for asset $i$,

$$
E_{t}\left[\delta^{\theta}\left(\frac{C_{t+1}}{C_{t}}\right)^{-\frac{\theta}{\psi}} R_{c, t+1}^{-(1-\theta)} R_{i, t+1}\right]=1
$$

where $W_{t}$ is wealth, $R_{i, t}$ is the gross return on asset $i$, and $R_{c, t}$ is the gross return on a claim to aggregate consumption. This implies that the log stochastic discount factor is 
given as

$$
m_{t+1}=\theta \ln (\delta)-\frac{\theta}{\psi} \Delta c_{t+1}-(1-\theta) r_{c, t+1},
$$

where lowercase letters denote logs to the corresponding uppercase letters. If investors suffer from money illusion in the sense that they discont real cash flows with a nominal discount factor the log stochastic discount factor can be written as

$$
\widehat{m}_{t+1}=m_{t+1}-\lambda \pi_{t+1}
$$

where $0 \leq \lambda \leq 1$ determines the degree of money illusion. $\lambda=1$ implies perfect money illusion, while $\lambda=0$ implies no money illusion.

We follow Bansal and Yaron (2004) and distinguish between the unobservable return on the claim to aggregate consumption, $R_{c, t+1}$, and the observable return on the dividend claim, $R_{m, t+1}$, i.e. the return on the market portfolio, and log-linearize these returns, cf. Campbell and Shiller (1988a):

$$
\begin{aligned}
r_{c, t+1} & =k_{c, 0}+k_{c, 1} p c_{t+1}-p c_{t}+\Delta c_{t+1}, \\
r_{m, t+1} & =k_{d, 0}+k_{d, 1} p d_{t+1}-p d_{t}+\Delta d_{t+1}
\end{aligned}
$$

$p c_{t}$ and $p d_{t}$ are short-hand notation for the log price-consumption ratio and log pricedividend ratio, respectively. $k_{i, 0}$ and $k_{i, 1}$ for $i=c, d$ are constants that are a function of the linearization point which typically is chosen to be the sample average of the ratio in question. ${ }^{6}$ More specifically, $k_{d, 1}$ is computed as $\exp (\overline{p d}) /[1+\exp (\overline{p d})]$ and $k_{d, 0}$ as $-\ln \left(k_{d, 1}\right)-\left(1-k_{d, 1}\right) \ln \left(1 / k_{d, 1}-1\right)$, where $\overline{p d}$ denotes the sample average of the pricedividend-ratio. Likewise for $k_{c, 1}$ and $k_{c, 0}$.

\subsection{Rational expectations}

Initially, we assume investors form rational expectations and consequently that consumption, dividends, and inflation have the following dynamics:

\footnotetext{
${ }^{6}$ Engsted, Pedersen, and Tanggaard (2012a) show that the upper bound for the mean approximation error is minimized by setting the linearization point equal to the unconditional mean of the ratio.
} 


$$
\begin{aligned}
\Delta c_{t+1} & =\mu_{c}+x_{c, t}+\sigma_{c} \eta_{c, t+1}, \\
\Delta d_{t+1} & =\mu_{d}+\phi x_{c, t}+\sigma_{d} \eta_{d, t+1}, \\
\pi_{t+1} & =\mu_{\pi}+x_{\pi, t}+\sigma_{\pi} \eta_{\pi, t+1}, \\
x_{c, t+1} & =\beta_{1} x_{c, t}+\beta_{2} x_{\pi, t}+\sigma_{x c} \varepsilon_{c, t+1}, \\
x_{\pi, t+1} & =\beta_{3} x_{\pi, t}+\sigma_{x \pi} \varepsilon_{\pi, t+1},
\end{aligned}
$$

where all shocks $\left(\eta_{i, t+1}, i=c, d, \pi ; \varepsilon_{i, t+1}, i=c, \pi\right)$ are mutually uncorrelated $i i d$ normally distributed with mean zero and variance one. Consumption growth, dividend growth, and inflation are all modelled as containing a small persistent predictable component. For inflation this component $\left(x_{\pi, t}\right)$ follows a pure $\mathrm{AR}(1)$ process, while for consumption and dividend growth we follow Burkhardt and Hasseltoft (2012) and allow the persistent component $\left(x_{c, t}\right)$ to be a function of the lagged inflation component in addition to the $\mathrm{AR}(1)$ component. In general, $\beta_{2}$ in (8) will be set equal to 0 under money illusion so it will only be allowed to differ from 0 when there is no money illusion. This setup creates a link between real consumption growth (and hence the stochastic discount factor) and expected inflation, thereby giving a rational alternative to money illusion for explaining the relation between the dividend yield and inflation. Note that dividend growth is driven in part by the persistent consumption growth component through the leverage parameter $\phi$. This feature of the model follows Bansal and Yaron (2004).

We consider the simplest possible setup that will deliver insights into the relation between the dividend-price ratio and future inflation and, hence, we do not allow for time-varying volatility. Our aim is not to develop a model that can explain all features of the data, but to focus on the dividend yield-inflation relationship, similar to what Campbell and Vuolteenaho (2004a,b) and Basak and Yan (2010) do. The model can, however, easily be extended to include time-varying volatility along the lines of Bansal and Yaron (2004).

In solving the model we first conjecture that the log price-consumption ratio is a linear function of the state variables:

$$
p c_{t}=A_{0}+A_{1} x_{c, t}+A_{2} x_{\pi, t}
$$

With joint log-normality the Euler equation for the consumption claim (allowing for 
potential money illusion),

$$
E_{t}\left[\exp \left\{\theta \ln (\delta)-\frac{\theta}{\psi} \Delta c_{t+1}+\theta r_{c, t+1}-\lambda \pi_{t+1}\right\}\right]=1
$$

can be written as:

$E_{t}\left[\theta \ln (\delta)-\frac{\theta}{\psi} \Delta c_{t+1}+\theta r_{c, t+1}-\lambda \pi_{t+1}\right]+\frac{1}{2} \operatorname{Var}_{t}\left[\theta \ln (\delta)-\frac{\theta}{\psi} \Delta c_{t+1}+\theta r_{c, t+1}-\lambda \pi_{t+1}\right]=0$

Inserting the data-generating processes for the state variables (5)-(9), the log-linearized return relation (3), and the log-price consumption ratio (10), we verify the conjectured solution. See Appendix 2 for additional details as well as the expressions for $A_{0}, A_{1}$ and $A_{2}$.

Next, we conjecture that the log price-dividend ratio is also a linear function of the state variables:

$$
p d_{t}=B_{0}+B_{1} x_{c, t}+B_{2} x_{\pi, t} .
$$

Again, with joint log-normality the Euler equation for the dividend claim (allowing for potential money illusion),

$$
E_{t}\left[\exp \left\{\theta \ln (\delta)-\frac{\theta}{\psi} \Delta c_{t+1}-(1-\theta) r_{c, t+1}+r_{m, t+1}-\lambda \pi_{t+1}\right\}\right]=1
$$

can be written as:

$$
\begin{aligned}
0 & =E_{t}\left[\theta \ln (\delta)-\frac{\theta}{\psi} \Delta c_{t+1}-(1-\theta) r_{c, t+1}+r_{m, t+1}-\lambda \pi_{t+1}\right] \\
& +\frac{1}{2} \operatorname{Var}_{t}\left[\theta \ln (\delta)-\frac{\theta}{\psi} \Delta c_{t+1}-(1-\theta) r_{c, t+1}+r_{m, t+1}-\lambda \pi_{t+1}\right] .
\end{aligned}
$$

Similar to the case with the price-consumption ratio we insert the data-generating processes for the state variables (5)-(9), the log-linearized return relations (3)-(4), the log priceconsumption ratio (10), and the log price-dividend ratio (11) to verify the conjectured solution (see Appendix 3 for additional details as well as the expression for $B_{0}$ ). The coefficients of interest in our case are $B_{1}$ and $B_{2}$ that are given as

$$
\begin{aligned}
B_{1} & =\frac{\phi-\frac{1}{\psi}}{1-k_{d, 1} \beta_{1}}, \\
B_{2} & =\frac{k_{d, 1} B_{1} \beta_{2}-\frac{\lambda}{\theta}}{1-k_{d, 1} \beta_{3}}
\end{aligned}
$$


Regarding the sign of $B_{1}$ we first see that the denominator is positive, while the sign of the numerator depends on the relative size of the leverage coefficient $\phi$ and the intertemporal elasticity of substitution $\psi ; B_{1}>0$ for high values of $\psi$ relative to $\phi$, and vice versa. In other words, for $\psi>1 / \phi$ higher expected growth leads investors to buy more assets driving up the price-dividend ratio, i.e. the substitution effect dominates. In contrast, for $\psi<1 / \phi$ the wealth effect dominates such that the price-dividend ratio decreases when expected growth increases.

The link between the price-dividend ratio and expected inflation is determined by $B_{2}$. Again, we see that the denominator is positive such that our main focus should be on the numerator. First, consider the case with money illusion, $0<\lambda \leq 1$, and no link between real consumption growth and expected inflation, $\beta_{2}=0$ in (8). Since $\lambda$ is nonnegative the sign of $B_{2}$ is determined by $\theta=(1-\gamma) /(1-1 / \psi)$. The empirical evidence of a negative relation between the dividend-price ratio and expected inflation can thus be explained by investors suffering from money illusion and having recursive preferences with the preference parameters $\psi$ and $\gamma$ simultaneously being either larger than one or smaller than one. In contrast, if either $\psi$ or $\gamma$ is above one and the other preference parameter is below one, then there will be a positive relation between the dividend-price ratio and expected inflation. Note that this positive relation will also arise if investors have time-seperable power utility in which case $\theta=1$, which is consistent with the findings by Basak and Yan (2010).

With no money illusion, $\lambda=0$, but a link between real consumption growth and expected inflation, $\beta_{2} \neq 0$, it is also possible to find a negative relation between the dividend-price ratio and expected inflation. This is the case if $B_{1}$ and $\beta_{2}$ are of the same sign. As mentioned earlier the sign of $B_{1}$ depends on the size of $\psi$ relative to $\phi$, while the sign of $\beta_{2}$ is more unclear and ultimately an empirical matter. Figure 3 shows the time series of real log consumption growth and log inflation measured over both 1 and 20 years. A possible link between real consumption growth and inflation is hard to verify in the short run; the correlation is 0.01 when measuring the series over one year. In contrast, over the long run a stronger link appears. The correlation is 0.40 when measuring the series over 20 years. This result could support a small positive value of $\beta_{2}$ and could potentially explain the negative relation between the dividend-price ratio and expected inflation if $\psi>1 / \phi$. In other words, when the substitution effect dominates the increase in expected consumption growth, as a consequence of an increase in expected inflation $\left(\beta_{2}>0\right)$, would lead to a larger increase in expected dividend growth (through $\left.\phi\right)$ than in expected returns (through $\psi$ ), and thereby drive down the dividend-price ratio creating 
the negative link between the ratio and expected inflation. If $\beta_{2}<0$ the wealth effect needs to dominate, i.e. $\psi<1 / \phi$, in order for the dividend-price ratio to be negatively related to expected inflation. In this case an increase in expected consumption growth as a consequence of a decrease in expected inflation $\left(\beta_{2}<0\right)$ would lead to a smaller increase in expected dividend growth (through $\phi$ ) than in expected returns (through $\psi$ ), and thereby drive up the dividend-price ratio. Burkhardt and Hasseltoft (2012) evaluate the correlation between inflation and consumption growth over various smaller sample periods and for the sample period 1965-2000 they find strong evidence of a negative correlation. In light of this evidence, we consider both positive and negative values of $\beta_{2}$ in our simulation study. ${ }^{7}$

\subsubsection{Simulation study based on rational expectations and money illusion}

To explore the implications from the above model in terms of multiperiod inflation predictability by the dividend-price ratio, we calibrate the model at the annual frequency such that it matches the mean, standard deviation and persistence of dividend growth, consumption growth, and inflation, respectively. The data-generating parameters and the results from inflation predictability regressions with horizons matching those in Table 1 are given in Table 3 for the case of money illusion, while Table 4 contains the corresponding descriptive statistics. For now we set $\beta_{2}=0$, i.e. we do not allow for a link between real consumption growth and expected inflation. In our benchmark scenario we set $\gamma=2$ and $\psi=2$. We will evaluate the sensitivity of our results to these parameter choices. The persistence parameters $\beta_{1}$ and $\beta_{3}$ are set equal to 0.90. Bansal and Yaron (2004) choose the value 0.979 for $\beta_{1}$ in their calibration at a monthly frequency $\left(\beta_{3}\right.$ does not appear in their model). For $\phi$ we follow Bansal and Yaron and set it equal to 3. The reported numbers are averages across 10,000 simulations each of length 142, which matches the length of the annual dataset used in our empirical analysis.

The first set of results in Panel A of Table 3 is for the case with no money illusion $(\lambda=0, \psi=2, \gamma=2)$. As expected from (13) there is no inflation predictability from the dividend-price ratio in this case; the slope coefficients and t-statistics are virtually zero. If we now allow for money illusion but assume investors have time-separable power utility $(\lambda=1, \psi=0.5, \gamma=2$, cf. Panel $\mathrm{B}$ in Table 3 ) we would expect to find a positive relation between the dividend-price ratio and expected inflation, cf. (13) and

\footnotetext{
${ }^{7}$ For the period 1927-2002, Campbell and Vuolteenaho (2004a,b) find a strongly positive relation between expected inflation and expected long-term dividend growth, in contrast to their anticipation of a negative relationship.
} 
Basak and Yan (2010). This is also exactly what we find in the simulation study. The slope coefficients are positive and strongly significant for all horizons. Note, however, that this is in direct contrast to the empirical results in Table 1 which give negative slope coefficients. If we allow for money illusion and recursive preferences $(\lambda=1, \psi=2, \gamma=2$, cf. Panel C) the simulation results line up much better with the empirical findings. The slope coefficients are significantly negative and they turn more negative as the horizon increases.

To ensure that our results do not come about due to unrealistic simulated data, Table 4 compares the mean, standard deviation, and persistence of actual dividend growth, consumption growth, inflation, and the price-dividend ratio to the simulated series. In general, the standard deviation of the simulated price-dividend ratio is a bit too small, and in the case of time-separable power utility $(\lambda=1, \psi=0.5, \gamma=2)$ the mean is also too low. However, overall we see a good match between the actual and simulated data.

Given the uncertainty about the size of the intertemporal elasticity of substitution, cf. section 3.1, we finally evaluate if it is possible to reproduce the empirical results with money illusion and $\psi<1$. Panel D of Table 3 shows that for $\psi=0.5$ we get results that line up very good with the empirical findings. However, in order to match the level of the price-dividend ratio when $\psi=0.5$ we need a very low degree of relative risk aversion, which contrasts with the usual perception of investors' degree of risk aversion. The results are shown for a risk-neutral investor $(\gamma=0)$, but for very small positive values of $\gamma$ the results are very similar. Higher values of $\gamma$ (yet still below 1) will lead to a higher mean price-dividend ratio (and a larger standard deviation), but the inflation predictability results will generally remain.

In general, higher relative risk aversion will increase the mean price-dividend ratio also when $\gamma$ and $\psi$ both are above one. In this case, higher relative risk aversion will in addition lead to less inflation predictability by the dividend-price ratio; the absolute value of $\theta=(1-\gamma) /(1-1 / \psi)$ will increase and hence the effect of money illusion will decrease, cf. (13). Likewise, only partial money illusion, $0<\lambda<1$, will lower the degree of inflation predictability. These implications are all supported by unreported simulation results. ${ }^{8}$

\footnotetext{
${ }^{8}$ Similar to the empirical results, the inflation predictability found in the simulation study drives a wedge between the degree of real and nominal return and dividend growth predictability by the dividendprice ratio (details are available upon request).
} 


\subsubsection{Simulation study based on rational expectations and no money illusion}

To evaluate a potential purely rational explanation of inflation predictability by the dividend-price ratio we now set $\lambda=0$ and $\beta_{2} \neq 0$. Again, we calibrate the model at the annual frequency such that it matches the mean, standard deviation and persistence of dividend growth, consumption growth, and inflation, respectively. And still, we pay attention to the size of the preference parameters needed in order to match both inflation predictability and the descriptive statistics of the price-dividend ratio. The inflation predictability results are reported in Table 5 and the descriptive statistics in Table 6 .

The first set of results in Panel A of Table 5 is for the case with a small positive link between real consumption growth and expected inflation $\left(\beta_{2}=0.01, \beta_{1}=0.9, \psi=2\right.$, $\gamma=2$ ), and as expected, cf. (13), we find a negative relation between the dividend-price ratio and expected inflation. Compared to the case with money illusion the degree of predictability is, however, slightly smaller. There is a great deal of uncertainty associated with $\beta_{2}$ both in terms of sign and size, so it is of interest to evaluate the sensitivity of our results to other values of the coefficient. The degree of inflation predictability increases with $\beta_{2}$, but all else equal, higher $\beta_{2}$ leads to unrealistic persistent consumption and dividend growth series. Hence, in order to match the observed degree of autocorrelation in consumption and dividend growth we need to lower $\beta_{1}$ when increasing $\beta_{2}$. Panel B in Table $5\left(\beta_{2}=0.1, \beta_{1}=0.5, \psi=2, \gamma=2\right)$ and the corresponding descriptive statistics in Table 6 show that it is possible to obtain a strong degree of inflation predictability and retaining realistic descriptive statistics without money illusion but with a relatively strong link between real consumption growth and expected inflation. Note, however, the very low volatility of the price-dividend ratio in this case.

Regarding the uncertainty about the sign of the link between real consumption growth and expected inflation, Panel $\mathrm{C}$ in Table 5 shows the results for a small negative value of $\beta_{2}\left(\beta_{2}=-0.01, \beta_{1}=0.9, \psi=0.15, \gamma=100\right)$. Now the wealth effect needs to dominate in order to generate a negative relation between the dividend-price ratio and expected inflation, i.e. $\psi<1 / \phi$. For all positive values of $\psi$ below $1 / 3$ the inflation predictability results remain qualitatively the same, i.e. a negative relation between real consumption growth and expected inflation and a low intertemporal elasticity of substitution can to some degree explain the empirical findings regarding inflation predictability by the dividend-price ratio. However, low values of $\psi$ will, all else equal, lead to an unrelatistic low level of the price-dividend ratio. In order to match the mean price-dividend ratio with $\psi=0.15$ the degree of relative risk aversion needs to be around 100, which is 
unrealistically high. Note that in contrast to the case with money illusion $\gamma$ has no impact on the time-variation in the price-dividend ratio and, hence, the degree of inflation predictability; it only influences the level of the ratio. Finally, we examine a stronger negative link between real consumption growth and expected inflation $\left(\beta_{2}=-0.1, \beta_{1}=0.5\right.$, $\psi=0.15, \gamma=45$, cf. Panel D). Again, we need to lower $\beta_{1}$ in order obtain consumption and dividend growth series with a realistic degree of persistence. Similar to the results in Panels $\mathrm{A}$ and $\mathrm{B}$ we see that a larger value of $\beta_{2}$ in absolute terms increases the degree of inflation predictability. Compared to the scenario in Panel $\mathrm{C}$ we now need a lower value of $\gamma$ to match the level of the price-dividend ratio, but $\gamma=45$ is still unrealistically high.

\subsection{Adaptive expectations}

To investigate the robustness of our findings in term of investors' expectation formation scheme, we also consider the case with adaptive expectations and money illusion. This expectation formation scheme is consistent with, for example, Modigliani and Cohn (1979) and Campbell and Vuolteenaho (2004a,b) in their analyses of money illusion. ${ }^{9}$ The setup and the solution methodology are the same as above except that the data-generating processes for the state variables are now given as:

$$
\begin{aligned}
\Delta c_{t+1} & =x_{c, t}+\sigma_{c} \eta_{c, t+1}, \\
x_{c, t} & =\rho_{c} \Delta c_{t}+\left(1-\rho_{c}\right) x_{c, t-1}, \\
\Delta d_{t+1} & =x_{d, t}+\sigma_{d} \eta_{d, t+1}, \\
x_{d, t} & =\rho_{d} \Delta d_{t}+\left(1-\rho_{d}\right) x_{d, t-1}, \\
\pi_{t+1} & =x_{\pi, t}+\sigma_{\pi} \eta_{\pi, t+1}, \\
x_{\pi, t} & =\rho_{\pi} \pi_{t}+\left(1-\rho_{\pi}\right) x_{\pi, t-1},
\end{aligned}
$$

where all shocks are mutually uncorrelated iid normally distributed with mean zero and variance one. Expected consumption growth, dividend growth, and inflation are now all determined as the exponentially declining moving average of their own past values. $\rho_{i}$ for $i=c, d, \pi$ determines the weight investors put on this period relative to earlier periods in their expectation formation scheme.

We conjecture the following solutions for the log-price-consumption ratio and log price-dividend ratio:

\footnotetext{
${ }^{9}$ See also Gelain and Lansing (2014) for an asset pricing model with adaptive expectations.
} 


$$
\begin{aligned}
& p c_{t}=C_{0}+C_{1} x_{c, t}+C_{2} x_{\pi, t} \\
& p d_{t}=D_{0}+D_{1} x_{c, t}+D_{2} x_{\pi, t}+D_{3} x_{d, t} .
\end{aligned}
$$

We verify this conjectured solution in Appendix 4 and 5 and show that the coefficients for the log price-dividend ratio (except $D_{0}$ which can be found in Appendix 5) are given as:

$$
\begin{aligned}
& D_{1}=\frac{-\frac{1}{\psi}}{1-k_{d, 1}}, \\
& D_{2}=\frac{-\frac{\lambda}{\theta}}{1-k_{d, 1}}, \\
& D_{3}=\frac{1}{1-k_{d, 1}},
\end{aligned}
$$

Similar to the case with rational expectations we see that the presence of money illusion can generate a negative link between the dividend-price ratio and expected inflation if investors have recursive preferences with the preference parameters $\psi$ and $\gamma$ simultaneously being either larger than one or smaller than one.

\subsubsection{Simulation study based on adaptive expectations and money illusion}

Similar to the case with rational expectations we calibrate the model at the annual frequency such that it matches the mean, standard deviation and persistence of dividend growth, consumption growth, and inflation, respectively. Table 7 shows the inflation predictability results and Table 8 the corresponding descriptive statistics. Overall, the conclusion is the same as with rational expectations. With no money illusion $(\lambda=0$, $\psi=2, \quad \gamma=2$; cf. Panel A in Table 7) inflation is not predictable by the dividend-price ratio. With money illusion and time-separable power utility $(\lambda=1, \psi=0.5, \gamma=2$; cf. Panel B) the dividend-price ratio predicts inflation with a positive sign. With money illusion and recursive preferences with $\psi$ and $\gamma$ simultaneously being larger than one $(\lambda=1, \psi=2, \gamma=2$; cf. Panel $\mathrm{C})$ there is a significantly negative relation between the dividend-price ratio and future inflation. Finally, for money illusion and recursive preferences with $\psi$ and $\gamma$ simultaneously being smaller than one $(\lambda=1, \psi=0.7, \gamma=0$; cf. Panel D) we need a very low degree of relative risk aversion in order to match both the inflation predictability results and the descriptive statistics of the price-dividend ratio. 
Again, these results are as expected based on the theoretical model and in general show that money illusion as a potential explanation for inflation predictability by the dividendprice ratio holds irrespective of investors forming rational or adaptive expectations.

\subsection{Main conclusions from the simulation studies}

The simulation studies confirm the quantitative and qualitative predictions from the economic model:

First, with no money illusion and no relation between expected inflation and real consumption growth, inflation is not predictable by the dividend-price ratio.

Second, with money illusion, time-separable power utility, and rational expectations (as in Basak and Yan, 2010), inflation is predictable by the dividend-price ratio with a positive slope coefficient.

Third, with money illusion, time-nonseparable preferences, and plausible values for the degree of relative risk aversion and the intertemporal rate of substitution, inflation is predictable by the dividend-price ratio with a negative slope coefficient, in accordance with the empirical evidence on US data. This result holds both with rational expectations and with non-rational (adaptive) expectations.

Finally, with no money illusion but with a positive link from expected inflation to real consumption growth, the negative inflation-dividend yield relationship appears for plausible preference parameters. With a negative link from expected inflation to real consumption growth, the negative inflation-dividend yield relationship still appears but in order to match the level of the price-dividend ratio we need unrealistically high levels of risk aversion.

\section{The Campbell-Vuolteenaho approach}

As mentioned in the Introduction, many recent empirical studies of money illusion are based on the Campbell and Vuolteenaho (2004a,b) framework, and in general the results show a positive relation between the dividend yield and a smoothed backward-looking non-rational measure of expected inflation, thus supporting the radical Modigliani and Cohn (1979) money illusion hypothesis. At first sight this result contrasts with our finding of a negative relation between the dividend yield and expected inflation. 
The Campbell-Vuolteenaho VAR based approach is somewhat complicated and requires many choices and simplifying assumptions to be made. Thus, it may not be robust to changes in these choices and assumptions. For example, Lee (2010) uses a tworegime VAR analysis to document a regime change over the period 1927-2007 and that the Modigliani-Cohn type money illusion explains the post war data but not the pre-war data. Lee finds it puzzling that the stock market apparently has become more subject to money illusion over time. Other studies that question the validity of the Modigliani-Cohn hypothesis include Summers (1983), Bekaert and Engstrom (2010), and Wei (2010). In this section we analyze the Campbell-Vuolteenaho methodology and apply it to our data in order to reconcile the apparently conflicting results.

\subsection{Description and discussion of the approach}

The idea of Campbell and Vuolteenaho (2004a,b) is to decompose the dividend-price ratio into three components: objectively (i.e. rationally) expected long-run dividend growth, a subjective (i.e. irrational) risk-premium, and a mispricing term which is the difference between the subjectively and objectively expected long-run dividend growth. A VAR model is then used to empirically estimate the objectively expected long-run dividend growth component as well as the objective risk-premium, and a particular regression is used to obtain the subjective risk-premium and the mispricing term based on these VAR estimated components. Finally, each of the three components comprising the dividend yield is regressed onto a measure of expected inflation. The Modigliani-Cohn type of money illusion requires the inflation coefficient to be positive in the mispricing equation.

The details of the approach are as follows. First, the risk-free rate is subtracted from returns and dividend growth to get excess returns and excess dividend growth, $r_{t+1+j}^{e}$ and $\Delta d_{t+1+j}^{e}$. Then, equation (1) is expressed as (where the term $c /(1-\rho)$ is abstracted from for convenience)

$$
\begin{aligned}
d_{t}-p_{t} & =\sum_{j=0}^{\infty} \rho^{j}\left(E_{t}^{O} r_{t+1+j}^{e}-E_{t}^{O} \Delta d_{t+1+j}^{e}\right) \\
& =\sum_{j=0}^{\infty} \rho^{j}\left(E_{t}^{S} r_{t+1+j}^{e}-E_{t}^{S} \Delta d_{t+1+j}^{e}\right) \\
& =-\sum_{j=0}^{\infty} \rho^{j} E_{t}^{O} \Delta d_{t+1+j}^{e}+\sum_{j=0}^{\infty} \rho^{j} E_{t}^{S} r_{t+1+j}^{e}+\left(\sum_{j=0}^{\infty} \rho^{j} E_{t}^{O} \Delta d_{t+1+j}^{e}-\sum_{j=0}^{\infty} \rho^{j} E_{t}^{S} \Delta d_{t+1+j}^{e}\right)
\end{aligned}
$$


where $E_{t}^{O}$ and $E_{t}^{S}$ denote objective and subjective expectations, respectively. The rational investors form objective expectations and the irrational investors form subjective expectations. The crucial assumption behind the first two lines of (22) is that both types of investors end up setting the same dividend-price ratio in the market. In Campbell and Vuolteenaho's words: "As long as the irrational investors simply use the present value formula with an erroneous expected growth rate, both sets of expectations must obey the accounting identity of the Gordon growth model." (Campbell and Vuolteenaho (2004a, p.4), (2004b, p.20)). The third line of (22) decomposes $\sum_{j=0}^{\infty} \rho^{j} E_{t}^{O} r_{t+1+j}^{e}$ in the first line into a subjective risk-premium and a mispricing component $\varepsilon_{t} \equiv \sum_{j=0}^{\infty} \rho^{j} E_{t}^{O} \Delta d_{t+1+j}^{e}-$ $\sum_{j=0}^{\infty} \rho^{j} E_{t}^{S} \Delta d_{t+1+j}^{e}$. As noted by Cohen, Polk, and Vuolteenaho (2005, p.646), this setup implies that $\sum_{j=0}^{\infty} \rho^{j} E_{t}^{O} \Delta d_{t+1+j}^{e}-\sum_{j=0}^{\infty} \rho^{j} E_{t}^{S} \Delta d_{t+1+j}^{e}$ is equal to $\sum_{j=0}^{\infty} \rho^{j} E_{t}^{O} r_{t+1+j}^{e}-$ $\sum_{j=0}^{\infty} \rho^{j} E_{t}^{S} r_{t+1+j}^{e}$, i.e. the expectational error in long-term dividend growth is equal to the expectational error in long-term returns. As seen, the third line of (22) is the decomposition of the dividend-price ratio into the three components: objective long-term dividend growth, a subjective risk-premium, and a mispricing term. Each component to be estimated based on a VAR model.

The VAR model contains excess log stock returns, the log dividend-price ratio, a measure of expected inflation, and additional predictor variables. From the estimated model the long-run objective risk-premium $\sum_{j=0}^{\infty} \rho^{j} E_{t}^{O} r_{t+1+j}^{e}$ can be directly obtained while the long-run objective dividend growth $\sum_{j=0}^{\infty} \rho^{j} E_{t}^{O} \Delta d_{t+1+j}^{e}$ is obtained as a residual from the observed dividend-price ratio and the long-run objective risk-premium: $\sum_{j=0}^{\infty} \rho^{j} E_{t}^{O} \Delta d_{t+1+j}^{e}=\sum_{j=0}^{\infty} \rho^{j} E_{t}^{O} r_{t+1+j}^{e}-\left(d_{t}-p_{t}\right)$.

Next, Campbell and Vuolteenaho estimate the subjective risk-premium as the fitted value in a regression of the VAR generated $\sum_{j=0}^{\infty} \rho^{j} E_{t}^{O} r_{t+1+j}^{e}$ on a subjective risk-premium proxy, $R P_{t}$ (for example, the relative volatility of stocks vs. that of bonds):

$$
\sum_{j=0}^{\infty} \rho^{j} E_{t}^{O} r_{t+1+j}^{e}=\alpha+\beta R P_{t}+\varepsilon_{t} .
$$

The mispricing component is then the residuals, $\widehat{\varepsilon}_{t}$, from this regression. As emphasized by Campbell and Vuolteenaho (2004a, p.6), this way of obtaining the mispricing component assumes that mispricing is independent of the subjective risk-premium.

Finally, the three estimated components comprising the dividend yield (objective expected long-run dividend growth, i.e. the first term in the third line of (22), the subjective risk-premium, i.e. the second term in the third line of (22) which is estimated 
as $\widehat{\beta} R P_{t}$, and the mispricing component $\widehat{\varepsilon}_{t}$, i.e. the third term in the third line of $\left.(22)\right)$ are regressed onto the measure of expected inflation, $\widehat{\pi}_{t}$ :

$$
\begin{aligned}
-\sum_{j=0}^{\infty} \rho^{j} E_{t}^{O} \Delta d_{t+1+j}^{e} & =\alpha_{d}+\kappa_{d} \widehat{\pi}_{t}+\varepsilon_{d, t}, \\
\widehat{\beta} R P_{t} & =\alpha_{r}+\kappa_{r} \widehat{\pi}_{t}+\varepsilon_{r, t}, \\
\widehat{\varepsilon}_{t} & =\alpha_{m}+\kappa_{m} \widehat{\pi}_{t}+\varepsilon_{m, t} .
\end{aligned}
$$

In their main analysis, Campbell and Vuolteenaho use an exponentially declining moving average of past inflation rates as their measure of expected inflation.

Using the above approach on US data, Campbell and Vuolteenaho find strong support for the Modigliani-Cohn hypothesis. In the regression of mispricing on expected inflation measured by smoothed past inflation they find a positive and strongly significant coefficient with an $R^{2}$ of $78 \%$.

The Campbell-Vuolteenaho approach is based on a VAR model and, thus, is subject to the well-known limitations of VAR modeling. Linear VAR models may be econometrically misspecified, e.g. non-constant parameters (see the next sub-section), and implied long-horizon forecasts from low-order VAR models, as in (22), may be dubious (cf. e.g. Cochrane (2008) and Engsted and Pedersen (2010)). In addition, the CampbellVuolteenaho methodology makes several simplifying and potentially critical assumptions in order to identify the various components. First, it is assumed that the rational and irrational investors set the same dividend-price ratio in the market. This assumption makes it possible to back out the long-run objective dividend growth component from the observed dividend-price ratio and the long-run objective risk-premium. As noted by Brunnermeier and Julliard (2008), this assumption is equivalent to assuming that the irrational investors understand the iterated accounting identity, i.e. equation (1). Chen, Lung, and Wang (2009) present an analysis where the two types of investors do not set the same dividend-price ratio. In fact, in their analysis the mispricing term is defined as the difference between the actual dividend-price ratio and the VAR generated 'rational' dividend-price ratio. By using this measure, Chen et al. find that the Modigliani-Cohn type of money illusion may explain the level, but not the volatility, of mispricing in the US stock market.

Second, and related to the first point, there may be problems backing out the dividend growth component as a residual. Following the critique by Chen and Zhao (2009) and the later rebuttal by Engsted, Pedersen, and Tanggaard (2012b), Acker and Duck 
(2013a) investigate the effect of backing out $\sum_{j=0}^{\infty} \rho^{j} E_{t}^{O} \Delta d_{t+1+j}^{e}$ compared to estimating the component directly, which is possible if excess dividend growth is included in the VAR model. Acker and Duck find, in concordance with Engsted et al., that given the VAR model is common across backing out $\sum_{j=0}^{\infty} \rho^{j} E_{t}^{O} \Delta d_{t+1+j}^{e}$ and computing it directly, and given that this VAR model contains the dividend-price ratio, the two approaches give the same qualitative conclusions. In any case, even if the requirements stated in Engsted et al. are fulfilled, the decomposition may be sensitive to which additional state variables are included (cf. Campbell, 1991; Campbell and Ammer, 1993).

Third, the mispricing measure may depend on the chosen subjective risk-premium proxy and in general it is assumed that the mispricing component is independent of this proxy, cf. equation (23). As noted by Brunnermeier and Julliard (2008), this assumption is arbitrary. (Bekaert and Engstrom (2010) make a similar point).

In the following sub-section we apply Campbell and Vuolteenaho's approach on our data and investigate the robustness of the results in various ways.

\subsection{Empirical results}

In implementing the Campbell-Vuolteenaho approach we need a proxy for the subjective risk-premium, $R P_{t}$. We follow Asness (2000, 2003), Campbell and Vuolteenaho (2004a,b) and Acker and Duck (2013a,b) and use the relative volatility of stocks vs. that of bonds, $\sigma_{s} / \sigma_{b}$. In addition to the variables used to obtain the results in Table 1, Robert Shiller's dataset also contains a long-term government bond yield (the 10-year yield from 1953 and onwards). Based on these yields we compute constant-maturity (10 years) bond returns and subsequently $\sigma_{s} / \sigma_{b}$ using a rolling window of 10 years. We compute log excess returns by subtracting the lagged log 1-year interest rate (also available in Robert Shiller's dataset) from the log nominal returns computed earlier. Finally, we need a measure of expected inflation. We follow Campbell and Vuolteenaho (2004a,b) and use both the long-term bond yield and smoothed inflation computed as the exponentially declining moving average of past inflation rates:

$$
\widehat{\pi}_{t}=\rho_{\pi} \pi_{t}+\left(1-\rho_{\pi}\right) \widehat{\pi}_{t-1}
$$

We consider three values of the smoothing parameter, $\rho_{\pi}=(0.1,0.5,0.9)$, and four different sample periods (including the period analyzed by Campbell and Vuolteenaho, i.e. 1927-2002) in order to evalute the robustness of the findings over time. 
Table 9 shows the results based on a first-order VAR model similar to the one used by Campbell and Vuolteenaho, i.e. the variables included are log excess returns, the log dividend-price ratio, a measure of expected inflation, and our proxy for the subjective risk-premium, $\sigma_{s} / \sigma_{b}$. Due to the construction of $\sigma_{s} / \sigma_{b}$ the samples in Table 9 begin in 1881 at the earliest. Using smoothed past inflation with $\rho_{\pi}=0.5$ and considering the sample period, 1927-2002, we obtain results which are qualitatively similar to those obtained by Campbell and Vuolteenaho when also using the relative volatility of stocks vs. that of bonds as proxy for the subjective risk-premium (Table 4 in Campbell and Vuolteenaho, 2004a): Objectively expected long-run dividend growth is unrelated to expected inflation $\left(\kappa_{d}=0\right)$, the subjective risk-premium is negatively related to expected inflation $\left(\kappa_{r}<0\right)$, and mispricing is positively related to expected inflation $\left(\kappa_{m}>0\right)$ although with an $R^{2}=22 \%$ which is smaller than in Campbell and Vuolteenaho's analysis. Using a different proxy for the subjective risk-premium (the cross-sectional beta premium by Polk, Thomson, and Vuolteenaho, 2006), Campbell and Voulteenaho find a positive relation between objectively expected long-run dividend growth and expected inflation $\left(\kappa_{d}<0\right)$, but apart from that their results are robust across a number of alternative VAR specifications, including different data frequency and higher-order VAR models. Campbell and Vuolteenaho do not, however, evaluate the robustness of their results across different sample periods. With $\rho_{\pi}=0.5$ we find some sensitivity of the results to the sample period. This is especially the case for $\kappa_{d}$ and $\kappa_{r}$, while $\kappa_{m}$ (the mispricing coefficient) across all sub-samples turns out to be significantly positive. ${ }^{10}$

When measuring expected inflation as the exponentially declining moving average of past inflation rates it is not clear which value of the smoothing parameter to use and what the consequences are hereof in relation to the link between expected inflation and the three components of the dividend-price ratio. Table 9 also contains the results for $\rho_{\pi}=0.1$ and 0.9 , and comparing these to those based on $\rho_{\pi}=0.5$ we see that the conclusions are not robust to the choice of $\rho_{\pi}$. For example, for $\rho_{\pi}=0.1$ and the sample period 1927-2002 $\kappa_{d}$ is now postive and strongly significant and we can no longer reject the null hypothesis of $\kappa_{m}=0$, i.e. the mispricing component is no longer significant. With $\rho_{\pi}=0.1$ we also see a larger degree of sub-sample instability. Comparing the results for 1881-1945 to those for 1946-2012 we see that $\kappa_{d}$ goes from significantly negative to significantly positive, $\kappa_{r}$ goes from positive to negative (in both cases the coefficient cannot be rejected to be equal to zero in contrast to the sample period 1927-2002), and

\footnotetext{
${ }^{10}$ Lee (2010) and Acker and Duck (2013a) also apply the Campbell-Vuolteenaho approach across different sample periods and likewise find evidence of sub-sample instability in relation to the three components' relation to expected inflation.
} 
$\kappa_{m}$ goes from significantly positive to insignificantly positive.

As an alternative to smoothed past inflation as a measure for expected inflation Campbell and Vuolteenaho also consider the nominal yield on 10-year Treasury bonds in part of their initial analysis, but not in the VAR model and subsequent regressions as outlined in section 4.1. As a further robustness analysis of the Campbell-Vuolteenaho approach, Table 9 shows the results when replacing smoothed past inflation with the longterm bond yield as the measure of expected inflation. The results reveal large sensitivity to the choice of expected inflation measure: for all sample periods objectively expected

long-run dividend growth is now negatively related to expected inflation $\left(\kappa_{d}>0\right)$ and, interestingly, mispricing is now negatively related to expected inflation $\left(\kappa_{m}<0\right)$. Since the long-term bond yield is a forward-looking measure of inflation, this result fits nicely with our results in section 2.2 showing that actual long-term inflation is negatively related to the lagged dividend-price ratio. Thus, using a forward-looking measure of inflation within the Campbell-Vuolteenaho methodology casts doubts on the Modigliani-Cohn type money illusion, although it still does indicate some kind of money illusion.

The results in Table 9 overall show that the conclusions based on the CampbellVuolteenhao approach in relation to the presence of money illusion are sensitive to the sample period and the measure of expected inflation. In contrast, our direct regression approach suggested in section 2, which uses actual future inflation instead of a constructed measure of expected inflation, shows great stability over time (see Figure 2).

\section{Concluding remarks}

We have documented that in annual US data since 1871 long-horizon inflation is strongly predictable by the dividend-price ratio with a negative slope coefficient. An interesting implication of this result is that real stock returns are more predictable by the dividendprice ratio than nominal stock returns. The result poses a challenge to rational asset pricing models in which the dividend-price ratio does not vary with expected inflation.

We develop a consumption-based model with recursive preferences featuring nonrationality in the form of money illusion in order to explain the negative relation between the dividend-price ratio and future inflation. With plausible parameter values the model is able to match the salient features of the data, including the negative dividend-price ratio/inflation relation. This holds irrespective of whether expectations are rational or non-rational (adaptive). Our analysis confirms the result in earlier studies that the stock 
market potentially suffers from money illusion, although not necessarily of the ModiglianiCohn type which has been the conclusion in most of the earlier literature. Our analysis also offers another potential explanation of the negative relation between the dividendprice ratio and future inflation. A version of our economic model allows for a link between real consumption growth and expected inflation, and we show that a positive link (and no money illusion) to some degree can explain the empirical findings.

The negative predictive relationship between the dividend-price ratio and future longterm inflation is in general robust across subsamples. However, the data from the 1980s and 1990s do indicate a structural shift in the relationship, possibly caused by a stock market bubble. A detailed analysis of this is complicated by the fact that the analysis requires observations for inflation measured over several years. It will be important in future research to investigate whether the negative dividend yield-inflation relationship we have documented for most of the period since 1871, continues to hold in more recent data.

\section{Appendices}

\section{Appendix 1. The bootstrap procedure}

The general scheme in the bootstrap procedure to test the null hypothesis of no predictability, while accounting for potential small-sample bias, is as follows:

1. Use OLS to estimate

$$
y_{t, t+k}=\alpha_{k}+\beta_{k}\left(d_{t}-p_{t}\right)+\varepsilon_{t+k},
$$

where $y_{t, t+k}=\left\{\pi_{t, t+k}, r_{t, t+k}, r_{t, t+k}-\pi_{t, t+k},\right\}$ to obtain an estimate of $\beta_{k}$, denoted $\widehat{\beta}_{k}$, for $k=\{1,5,10,15,20\}$.

2. Use OLS to estimate

$$
\begin{aligned}
y_{t+1} & =\alpha+\beta\left(d_{t}-p_{t}\right)+\varepsilon_{t+1}, \\
\left(d_{t+1}-p_{t+1}\right) & =\varpi+\eta\left(d_{t}-p_{t}\right)+\omega_{t+1},
\end{aligned}
$$

where $y_{t+1}=\left\{\pi_{t+1}, r_{t+1}, r_{t+1}-\pi_{t+1},\right\}$, i.e. we here consider one-period inflation, nominal returns, and real returns. This yields the following relevant estimates: $\widehat{\alpha}$, 
$\widehat{\varpi}, \widehat{\eta}$, and $\widehat{\Omega}$, where $\Omega$ is the covariance matrix of the residuals:

$$
\Omega=\left[\begin{array}{cc}
\sigma_{\varepsilon}^{2} & \sigma_{\varepsilon \omega} \\
\sigma_{\varepsilon \omega} & \sigma_{\omega}^{2}
\end{array}\right] .
$$

3. Generate $T=142$ random numbers of $\left(\varepsilon_{t+1}, \omega_{t+1}\right)$ from a multivariate normal distribution with covariance matrix $\widehat{\Omega}$. We denote these simulated error terms $\left(\varepsilon_{t+1}^{*}, \omega_{t+1}^{*}\right)$.

4. Generate a random initial value of $d_{t}-p_{t}$ :

$$
d_{1}^{*}-p_{1}^{*} \sim \mathcal{N}\left(\overline{d-p}, \widehat{\sigma}_{d p}^{2}\right)
$$

where $\overline{d-p}$ and $\widehat{\sigma}_{d p}^{2}$ denote the sample average and the variance, respectively, of the dividend-price ratio.

5. Use $\widehat{\varpi}$ and $\widehat{\eta}$ together with the generated values of $\omega_{t+1}$ and the initial value in steps 3 and 4 to obtain $T=142$ observations of $d_{t}-p_{t}$ :

$$
\widehat{\varpi}+\widehat{\eta}\left(d_{t}^{*}-p_{t}^{*}\right)+\omega_{t+1}^{*} \rightarrow d_{t+1}^{*}-p_{t+1}^{*}
$$

6. Use $\widehat{\alpha}$ together with the generated values of $\varepsilon_{t+1}$ to obtain $T=142$ observations of $y_{t}$ under the null hypothesis $\beta=0$ :

$$
\widehat{\alpha}+\varepsilon_{t+1}^{*} \rightarrow y_{t+1}^{*}
$$

7. Construct multi-period inflation/returns $y_{t, t+k}^{*}=\sum_{i=0}^{k-1} y_{t+1+i}^{*}$ for $k=\{1,5,10,15,20\}$ using the one-period series. The following steps are carried out for all relevant values of $k$.

8. Use OLS to estimate

$$
y_{t, t+k}^{*}=\alpha_{k}+\beta_{k}\left(d_{t}^{*}-p_{t}^{*}\right)+\varepsilon_{t+k}^{*},
$$

and denote the estimated slope coefficient $\widetilde{\beta}_{k}^{(1)}$.

9. Repeat steps $3-8 M=10,000$ times to obtain $\widetilde{\beta}_{k}^{(1)}, \widetilde{\beta}_{k}^{(2)}, \ldots, \widetilde{\beta}_{k}^{(M)}$. 
10. Compute the (upper) one-sided p-value under the null hypothesis as

$$
P\left(\widetilde{\beta}_{k}>\widehat{\beta}_{k}\right)=\frac{1}{M} \sum_{i=1}^{M} I\left[\widetilde{\beta}_{k}^{(i)}>\widehat{\beta}_{k}\right]
$$

where $I[\cdot]$ is an indicator function.

11. Compute the bias as

$$
\operatorname{bias}\left(\widehat{\beta}_{k}\right)=\frac{1}{M} \sum_{i=1}^{M} \widetilde{\beta}_{k}^{(i)} \text {. }
$$

We have evaluated the robustness of the results in a number of ways. First, we have done the analysis using residual-based bootstrapping in step 2 as an alternative to parametric bootstrapping. Second, we have adjusted $\widehat{\eta}$ for bias before generating data in step 5. Finally, given a fairly persistent inflation process we have $i$ ) generated data such that $\varepsilon_{t+1}^{*}$ follows an $\operatorname{AR}(1)$ process, $\left.i i\right)$ made use of a block bootstrap, and iii) included lagged inflation as a predictor variable both in the predictive regression and in the bootstrap. None of these modifications of the bootstrap procedure outlined above changes the qualitative conclusions in the empirical analysis.

\section{Appendix 2. Solving for the price-consumption ratio under ra- tional expectations}

With joint log-normality the Euler equation for the consumption claim (allowing for potential money illusion) can be written as:

$E_{t}\left[\theta \ln (\delta)-\frac{\theta}{\psi} \Delta c_{t+1}+\theta r_{c, t+1}-\lambda \pi_{t+1}\right]+\frac{1}{2} \operatorname{Var}_{t}\left[\theta \ln (\delta)-\frac{\theta}{\psi} \Delta c_{t+1}+\theta r_{c, t+1}-\lambda \pi_{t+1}\right]=0$.

Inserting the data-generating processes for the state variables (5)-(9), the log-linearized return relation (3), and the conjectured log-price consumption ratio (10), the conditional 
mean is given by:

$$
\begin{aligned}
& E_{t}\left[\theta \ln (\delta)-\frac{\theta}{\psi} \Delta c_{t+1}+\theta r_{c, t+1}-\lambda \pi_{t+1}\right] \\
& =\theta \ln (\delta)-\frac{\theta}{\psi}\left(\mu_{c}+x_{c, t}\right)+\theta\left(k_{c, 0}+k_{c, 1}\left(A_{0}+A_{1}\left[\beta_{1} x_{c, t}+\beta_{2} x_{\pi, t}\right]+A_{2} \beta_{3} x_{\pi, t}\right)\right) \\
& -\theta\left(A_{0}+A_{1} x_{c, t}+A_{2} x_{\pi, t}\right)+\theta\left(\mu_{c}+x_{c, t}\right)-\lambda\left(\mu_{\pi}+x_{\pi, t}\right) \\
& =\theta \ln (\delta)-\frac{\theta}{\psi} \mu_{c}+\theta\left(k_{c, 0}+k_{c, 1} A_{0}-A_{0}+\mu_{c}\right)-\lambda \mu_{\pi} \\
& +x_{c, t}\left(-\frac{\theta}{\psi}+\theta k_{c, 1} A_{1} \beta_{1}-\theta A_{1}+\theta\right) \\
& +x_{\pi, t}\left(\theta k_{c, 1}\left(A_{1} \beta_{2}+A_{2} \beta_{3}\right)-\theta A_{2}-\lambda\right) .
\end{aligned}
$$

Likewise, the conditional variance is given by:

$$
\begin{aligned}
& \operatorname{Var}_{t}\left[\theta \ln (\delta)-\frac{\theta}{\psi} \Delta c_{t+1}+\theta r_{c, t+1}-\lambda \pi_{t+1}\right] \\
& =\operatorname{Var}_{t}\left(-\frac{\theta}{\psi} \sigma_{c} \eta_{c, t+1}+\theta k_{c, 1}\left(A_{1} \sigma_{x c} \varepsilon_{c, t+1}+A_{2} \sigma_{x \pi} \varepsilon_{\pi, t+1}\right)+\theta \sigma_{c} \eta_{c, t+1}-\lambda \sigma_{\pi} \eta_{\pi, t+1}\right) \\
& =\left(\theta-\frac{\theta}{\psi}\right)^{2} \sigma_{c}^{2}+\left(\theta k_{c, 1} A_{1} \sigma_{x c}\right)^{2}+\left(\theta k_{c, 1} A_{2} \sigma_{x \pi}\right)^{2}+\left(\lambda \sigma_{\pi}\right)^{2} .
\end{aligned}
$$

Solving for $A_{0}$ yields:

$$
\begin{aligned}
0 & =\theta \ln (\delta)-\frac{\theta}{\psi} \mu_{c}+\theta\left(k_{c, 0}+k_{c, 1} A_{0}-A_{0}+\mu_{c}\right)-\lambda \mu_{\pi} \\
& +\frac{1}{2}\left\{\left(\theta-\frac{\theta}{\psi}\right)^{2} \sigma_{c}^{2}+\left(\theta k_{c, 1} A_{1} \sigma_{x c}\right)^{2}+\left(\theta k_{c, 1} A_{2} \sigma_{x \pi}\right)^{2}+\left(\lambda \sigma_{\pi}\right)^{2}\right\}
\end{aligned}
$$

$\Uparrow$

$A_{0}=\frac{\theta \ln (\delta)-\frac{\theta}{\psi} \mu_{c}+\theta\left(k_{c, 0}+\mu_{c}\right)-\lambda \mu_{\pi}+\frac{1}{2}\left\{\left(\theta-\frac{\theta}{\psi}\right)^{2} \sigma_{c}^{2}+\left(\theta k_{c, 1} A_{1} \sigma_{x c}\right)^{2}+\left(\theta k_{c, 1} A_{2} \sigma_{x \pi}\right)^{2}+\left(\lambda \sigma_{\pi}\right)^{2}\right\}}{\theta\left(1-k_{c, 1}\right)}$

Solving for $A_{1}$ yields:

$$
\begin{aligned}
0 & =-\frac{\theta}{\psi}+\theta k_{c, 1} A_{1} \beta_{1}-\theta A_{1}+\theta \\
& \mathbb{1} \\
A_{1} & =\frac{1-\frac{1}{\psi}}{1-k_{c, 1} \beta_{1}}
\end{aligned}
$$


Solving for $A_{2}$ yields:

$$
\begin{aligned}
0 & =\theta k_{c, 1}\left(A_{1} \beta_{2}+A_{2} \beta_{3}\right)-\theta A_{2}-\lambda \\
& \mathbb{1} \\
A_{2} & =\frac{k_{c, 1} A_{1} \beta_{2}-\frac{\lambda}{\theta}}{1-k_{c, 1} \beta_{3}}
\end{aligned}
$$

\section{Appendix 3. Solving for the price-dividend ratio under rational expectations}

With joint log-normality the Euler equation for the dividend claim (allowing for potential money illusion) can be written as:

$$
\begin{aligned}
0 & =E_{t}\left[\theta \ln (\delta)-\frac{\theta}{\psi} \Delta c_{t+1}-(1-\theta) r_{c, t+1}+r_{m, t+1}-\lambda \pi_{t+1}\right] \\
& +\frac{1}{2} \operatorname{Var}_{t}\left[\theta \ln (\delta)-\frac{\theta}{\psi} \Delta c_{t+1}-(1-\theta) r_{c, t+1}+r_{m, t+1}-\lambda \pi_{t+1}\right] .
\end{aligned}
$$

Inserting the data-generating processes for the state variables (5)-(9), the log-linearized return relations (3)-(4), the log-price consumption ratio (10), and the log-price-dividend ratio (11), the conditional mean is given by:

$$
\begin{aligned}
& E_{t}\left[\theta \ln (\delta)-\frac{\theta}{\psi} \Delta c_{t+1}-(1-\theta) r_{c, t+1}+r_{m, t+1}-\lambda \pi_{t+1}\right] \\
& =\theta \ln (\delta)-\frac{\theta}{\psi}\left(\mu_{c}+x_{c, t}\right)-(1-\theta)\left(k_{c, 0}+k_{c, 1}\left(A_{0}+A_{1}\left[\beta_{1} x_{c, t}+\beta_{2} x_{\pi, t}\right]+A_{2} \beta_{3} x_{\pi, t}\right)\right) \\
& +(1-\theta)\left(A_{0}+A_{1} x_{c, t}+A_{2} x_{\pi, t}\right)-(1-\theta)\left(\mu_{c}+x_{c, t}\right) \\
& +\left(k_{d, 0}+k_{d, 1}\left(B_{0}+B_{1}\left[\beta_{1} x_{c, t}+\beta_{2} x_{\pi, t}\right]+B_{2} \beta_{3} x_{\pi, t}\right)\right)-\left(B_{0}+B_{1} x_{c, t}+B_{2} x_{\pi, t}\right) \\
& +\mu_{d}+\phi x_{c, t}-\lambda\left(\mu_{\pi}+x_{\pi, t}\right) \\
& =\theta \ln (\delta)-\frac{\theta}{\psi} \mu_{c}-(1-\theta)\left(k_{c, 0}+k_{c, 1} A_{0}-A_{0}+\mu_{c}\right)+k_{d, 0}+k_{d, 1} B_{0}-B_{0}+\mu_{d}-\lambda \mu_{\pi} \\
& +x_{c, t}\left(-\frac{\theta}{\psi}-(1-\theta)\left(k_{c, 1} A_{1} \beta_{1}-A_{1}+1\right)+k_{d, 1} B_{1} \beta_{1}-B_{1}+\phi\right) \\
& +x_{\pi, t}\left(-(1-\theta)\left(k_{c, 1}\left(A_{1} \beta_{2}+A_{2} \beta_{3}\right)-A_{2}\right)+k_{d, 1}\left(B_{1} \beta_{2}+B_{2} \beta_{3}\right)-B_{2}-\lambda\right)
\end{aligned}
$$


Likewise, the conditional variance is given by:

$$
\begin{aligned}
& \operatorname{Var}_{t}\left[\theta \ln (\delta)-\frac{\theta}{\psi} \Delta c_{t+1}-(1-\theta) r_{c, t+1}+r_{m, t+1}-\lambda \pi_{t+1}\right] \\
& =\operatorname{Var}_{t}\left[-\frac{\theta}{\psi} \sigma_{c} \eta_{c, t+1}-(1-\theta) k_{c, 1}\left(A_{1} \sigma_{x c} \varepsilon_{c, t+1}+A_{2} \sigma_{x \pi} \varepsilon_{\pi, t+1}\right)-(1-\theta) \sigma_{c} \eta_{c, t+1}\right. \\
& \left.+k_{d, 1}\left(B_{1} \sigma_{x c} \varepsilon_{c, t+1}+B_{2} \sigma_{x \pi} \varepsilon_{\pi, t+1}\right)+\sigma_{d} \eta_{d, t+1}-\lambda \sigma_{\pi} \eta_{\pi, t+1}\right] \\
& =\left(\theta-1-\frac{\theta}{\psi}\right)^{2} \sigma_{c}^{2}+\left((1-\theta) k_{c, 1} A_{1} \sigma_{x c}\right)^{2}+\left((1-\theta) k_{c, 1} A_{2} \sigma_{x \pi}\right)^{2}+\left(k_{d, 1} B_{1} \sigma_{x c}\right)^{2} \\
& +\left(k_{d, 1} B_{2} \sigma_{x \pi}\right)^{2}+\sigma_{d}^{2}+\left(\lambda \sigma_{\pi}\right)^{2}
\end{aligned}
$$

Solving for $B_{0}$ yields:

$$
\begin{aligned}
0 & =\theta \ln (\delta)-\frac{\theta}{\psi} \mu_{c}-(1-\theta)\left(k_{c, 0}+k_{c, 1} A_{0}-A_{0}+\mu_{c}\right)+k_{d, 0}+k_{d, 1} B_{0}-B_{0}+\mu_{d}-\lambda \mu_{\pi} \\
& +\frac{1}{2}\left\{\left(\theta-1-\frac{\theta}{\psi}\right)^{2} \sigma_{c}^{2}+\left[\left((1-\theta) k_{c, 1} A_{1}\right)^{2}+\left(k_{d, 1} B_{1}\right)^{2}\right] \sigma_{x c}^{2}\right\} \\
& +\frac{1}{2}\left\{\left[\left((1-\theta) k_{c, 1} A_{2}\right)^{2}+\left(k_{d, 1} B_{2}\right)^{2}\right] \sigma_{x \pi}^{2}+\sigma_{d}^{2}+\lambda^{2} \sigma_{\pi}^{2}\right\} \\
& \mathbb{\Downarrow} \\
B_{0} & =\frac{\theta \ln (\delta)-\frac{\theta}{\psi} \mu_{c}-(1-\theta)\left(k_{c, 0}+k_{c, 1} A_{0}-A_{0}+\mu_{c}\right)+k_{d, 0}+\mu_{d}-\lambda \mu_{\pi}}{1-k_{d, 1}} \\
& +\frac{\frac{1}{2}\left\{\left(\theta-1-\frac{\theta}{\psi}\right)^{2} \sigma_{c}^{2}+\left[\left((1-\theta) k_{c, 1} A_{1}\right)^{2}+\left(k_{d, 1} B_{1}\right)^{2}\right] \sigma_{x c}^{2}\right\}}{1-k_{d, 1}} \\
& +\frac{\left.\frac{1}{2}\left\{\left[(1-\theta) k_{c, 1} A_{2}\right)^{2}+\left(k_{d, 1} B_{2}\right)^{2}\right] \sigma_{x \pi}^{2}+\sigma_{d}^{2}+\lambda^{2} \sigma_{\pi}^{2}\right\}}{1-k_{d, 1}}
\end{aligned}
$$

Solving for $B_{1}$ yields (when inserting for $A_{1}$ ):

$$
\begin{aligned}
0 & =-\frac{\theta}{\psi}-(1-\theta)\left(k_{c, 1} A_{1} \beta_{1}-A_{1}+1\right)+k_{d, 1} B_{1} \beta_{1}-B_{1}+\phi \\
& \mathbb{1} \\
B_{1} & =\frac{\phi-\frac{1}{\psi}}{1-k_{d, 1} \beta_{1}}
\end{aligned}
$$


Solving for $B_{2}$ yields (when inserting for $A_{2}$ ):

$$
\begin{aligned}
0 & =-(1-\theta)\left(k_{c, 1}\left(A_{1} \beta_{2}+A_{2} \beta_{3}\right)-A_{2}\right)+k_{d, 1}\left(B_{1} \beta_{2}+B_{2} \beta_{3}\right)-B_{2}-\lambda \\
& \Uparrow \\
B_{2} & =\frac{k_{d, 1} B_{1} \beta_{2}-\frac{\lambda}{\theta}}{1-k_{d, 1} \beta_{3}}
\end{aligned}
$$

\section{Appendix 4. Solving for the price-consumption ratio under adap- tive expectations}

With joint log-normality the Euler equation for the consumption claim (allowing for potential money illusion) can be written as:

$E_{t}\left[\theta \ln (\delta)-\frac{\theta}{\psi} \Delta c_{t+1}+\theta r_{c, t+1}-\lambda \pi_{t+1}\right]+\frac{1}{2} \operatorname{Var}_{t}\left[\theta \ln (\delta)-\frac{\theta}{\psi} \Delta c_{t+1}+\theta r_{c, t+1}-\lambda \pi_{t+1}\right]=0$

Inserting the data-generating processes for the state variables (14)-(19), the log-linearized return relation (3), and the conjectured log-price consumption ratio (20), the conditional mean is given by:

$$
\begin{aligned}
& E_{t}\left[\theta \ln (\delta)-\frac{\theta}{\psi} \Delta c_{t+1}+\theta r_{c, t+1}-\lambda \pi_{t+1}\right] \\
& =\theta \ln (\delta)-\frac{\theta}{\psi} x_{c, t}+\theta\left(k_{c, 0}+k_{c, 1}\left(C_{0}+C_{1} x_{c, t}+C_{2} x_{\pi, t}\right)\right) \\
& -\theta\left(C_{0}+C_{1} x_{c, t}+C_{2} x_{\pi, t}\right)+\theta x_{c, t}-\lambda x_{\pi, t} \\
& =\theta \ln (\delta)+\theta\left(k_{c, 0}+k_{c, 1} C_{0}-C_{0}\right) \\
& +x_{c, t}\left(-\frac{\theta}{\psi}+\theta k_{c, 1} C_{1}-\theta C_{1}+\theta\right) \\
& +x_{\pi, t}\left(\theta k_{c, 1} C_{2}-\theta C_{2}-\lambda\right) .
\end{aligned}
$$

Likewise, the conditional variance is given by:

$$
\begin{aligned}
& \operatorname{Var}_{t}\left[\theta \ln (\delta)-\frac{\theta}{\psi} \Delta c_{t+1}+\theta r_{c, t+1}-\lambda \pi_{t+1}\right] \\
& =\operatorname{Var}_{t}\left(-\frac{\theta}{\psi} \sigma_{c} \eta_{c, t+1}+\theta k_{c, 1}\left(C_{1} \rho_{c} \sigma_{c} \eta_{c, t+1}+C_{2} \rho_{\pi} \sigma_{\pi} \eta_{\pi, t+1}\right)+\theta \sigma_{c} \eta_{c, t+1}-\lambda \sigma_{\pi} \eta_{\pi, t+1}\right) \\
& =\left(\theta-\frac{\theta}{\psi}\right)^{2} \sigma_{c}^{2}+\left(\theta k_{c, 1} C_{1} \rho_{c} \sigma_{c}\right)^{2}+\left(\theta k_{c, 1} C_{2} \rho_{\pi} \sigma_{\pi}\right)^{2}+\left(\lambda \sigma_{\pi}\right)^{2} .
\end{aligned}
$$


Solving for $C_{0}$ yields:

$$
\begin{aligned}
0 & =\theta \ln (\delta)+\theta\left(k_{c, 0}+k_{c, 1} C_{0}-C_{0}\right) \\
& +\frac{1}{2}\left\{\left(\theta-\frac{\theta}{\psi}\right)^{2} \sigma_{c}^{2}+\left(\theta k_{c, 1} C_{1} \rho_{c} \sigma_{c}\right)^{2}+\left(\theta k_{c, 1} C_{2} \rho_{\pi} \sigma_{\pi}\right)^{2}+\left(\lambda \sigma_{\pi}\right)^{2}\right\} \\
& \Uparrow \\
C_{0} & =\frac{\theta \ln (\delta)+\theta k_{c, 0}+\frac{1}{2}\left\{\left(\theta-\frac{\theta}{\psi}\right)^{2} \sigma_{c}^{2}+\left(\theta k_{c, 1} C_{1} \rho_{c} \sigma_{c}\right)^{2}+\left(\theta k_{c, 1} C_{2} \rho_{\pi} \sigma_{\pi}\right)^{2}+\left(\lambda \sigma_{\pi}\right)^{2}\right\}}{\theta\left(1-k_{c, 1}\right)} .
\end{aligned}
$$

Solving for $C_{1}$ yields:

$$
\begin{aligned}
0 & =-\frac{\theta}{\psi}+\theta k_{c, 1} C_{1}-\theta C_{1}+\theta \\
& \mathbb{} \\
C_{1} & =\frac{1-\frac{1}{\psi}}{1-k_{c, 1}} .
\end{aligned}
$$

Solving for $C_{2}$ yields:

$$
\begin{aligned}
0 & =\theta k_{c, 1} C_{2}-\theta C_{2}-\lambda \\
& \mathbb{1} \\
C_{2} & =\frac{-\frac{\lambda}{\theta}}{1-k_{c, 1}} .
\end{aligned}
$$

\section{Appendix 5. Solving for the price-dividend ratio under adaptive expectations}

With joint log-normality the Euler equation for the dividend claim (allowing for potential money illusion) can be written as:

$$
\begin{aligned}
0 & =E_{t}\left[\theta \ln (\delta)-\frac{\theta}{\psi} \Delta c_{t+1}-(1-\theta) r_{c, t+1}+r_{m, t+1}-\lambda \pi_{t+1}\right] \\
& +\frac{1}{2} \operatorname{Var}_{t}\left[\theta \ln (\delta)-\frac{\theta}{\psi} \Delta c_{t+1}-(1-\theta) r_{c, t+1}+r_{m, t+1}-\lambda \pi_{t+1}\right] .
\end{aligned}
$$

Inserting the data-generating processes for the state variables (14)-(19), the log-linearized return relations (3)-(4), the log-price consumption ratio (20), and the log-price-dividend 
ratio (21), the conditional mean is given by:

$$
\begin{aligned}
& E_{t}\left[\theta \ln (\delta)-\frac{\theta}{\psi} \Delta c_{t+1}-(1-\theta) r_{c, t+1}+r_{m, t+1}-\lambda \pi_{t+1}\right] \\
& =\theta \ln (\delta)-\frac{\theta}{\psi} x_{c, t}-(1-\theta)\left(k_{c, 0}+k_{c, 1}\left(C_{0}+C_{1} x_{c, t}+C_{2} x_{\pi, t}\right)\right) \\
& +(1-\theta)\left(C_{0}+C_{1} x_{c, t}+C_{2} x_{\pi, t}\right)-(1-\theta) x_{c, t} \\
& +\left(k_{d, 0}+k_{d, 1}\left(D_{0}+D_{1} x_{c, t}+D_{2} x_{\pi, t}+D_{3} x_{d, t}\right)\right)-\left(D_{0}+D_{1} x_{c, t}+D_{2} x_{\pi, t}+D_{3} x_{d, t}\right) \\
& +x_{d, t}-\lambda x_{\pi, t} \\
& =\theta \ln (\delta)-(1-\theta)\left(k_{c, 0}+k_{c, 1} C_{0}-C_{0}\right)+k_{d, 0}+k_{d, 1} D_{0}-D_{0} \\
& +x_{c, t}\left(-\frac{\theta}{\psi}-(1-\theta)\left(k_{c, 1} C_{1}-C_{1}+1\right)+k_{d, 1} D_{1}-D_{1}\right) \\
& +x_{\pi, t}\left(-(1-\theta)\left(k_{c, 1} C_{2}-C_{2}\right)+k_{d, 1} D_{2}-D_{2}-\lambda\right) \\
& +x_{d, t}\left(k_{d, 1} D_{3}-D_{3}+1\right)
\end{aligned}
$$

Likewise, the conditional variance is given by:

$$
\begin{aligned}
& \operatorname{Var}_{t}\left[\theta \ln (\delta)-\frac{\theta}{\psi} \Delta c_{t+1}-(1-\theta) r_{c, t+1}+r_{m, t+1}-\lambda \pi_{t+1}\right] \\
& =\operatorname{Var}_{t}\left[-\frac{\theta}{\psi} \sigma_{c} \eta_{c, t+1}-(1-\theta) k_{c, 1}\left(C_{1} \rho_{c} \sigma_{c} \eta_{c, t+1}+C_{2} \rho_{\pi} \sigma_{\pi} \eta_{\pi, t+1}\right)-(1-\theta) \sigma_{c} \eta_{c, t+1}\right. \\
& \left.+k_{d, 1}\left(D_{1} \rho_{c} \sigma_{c} \eta_{c, t+1}+D_{2} \rho_{\pi} \sigma_{\pi} \eta_{\pi, t+1}+D_{3} \rho_{d} \sigma_{d} \eta_{d, t+1}\right)+\sigma_{d} \eta_{d, t+1}-\lambda \sigma_{\pi} \eta_{\pi, t+1}\right] \\
& =\left(\theta-1-\frac{\theta}{\psi}\right)^{2} \sigma_{c}^{2}+\left((1-\theta) k_{c, 1} C_{1} \rho_{c} \sigma_{c}\right)^{2}+\left((1-\theta) k_{c, 1} C_{2} \rho_{\pi} \sigma_{\pi}\right)^{2} \\
& +\left(k_{d, 1} D_{1} \rho_{c} \sigma_{c}\right)^{2}+\left(k_{d, 1} D_{2} \rho_{\pi} \sigma_{\pi}\right)^{2}+\left(k_{d, 1} D_{3} \rho_{d} \sigma_{d}\right)^{2}+\sigma_{d}^{2}+\left(\lambda \sigma_{\pi}\right)^{2} \\
& =\left[\left(\theta-1-\frac{\theta}{\psi}\right)^{2}+\left((1-\theta) k_{c, 1} \rho_{c} C_{1}\right)^{2}+\left(k_{d, 1} D_{1} \rho_{c}\right)^{2}\right] \sigma_{c}^{2}+\left[\left(k_{d, 1} D_{3} \rho_{d}\right)^{2}+1\right] \sigma_{d}^{2} \\
& +\left[\left((1-\theta) k_{c, 1} C_{2} \rho_{\pi}\right)^{2}+\left(k_{d, 1} D_{2} \rho_{\pi}\right)^{2}+\lambda^{2}\right] \sigma_{\pi}^{2} .
\end{aligned}
$$


Solving for $D_{0}$ yields:

$$
\begin{aligned}
0 & =\theta \ln (\delta)-(1-\theta)\left(k_{c, 0}+k_{c, 1} C_{0}-C_{0}\right)+k_{d, 0}+k_{d, 1} D_{0}-D_{0} \\
& +\frac{1}{2}\left\{\left[\left(\theta-1-\frac{\theta}{\psi}\right)^{2}+\left((1-\theta) k_{c, 1} \rho_{c} C_{1}\right)^{2}+\left(k_{d, 1} D_{1} \rho_{c}\right)^{2}\right] \sigma_{c}^{2}+\left[\left(k_{d, 1} D_{3} \rho_{d}\right)^{2}+1\right] \sigma_{d}^{2}\right\} \\
& +\frac{1}{2}\left[\left((1-\theta) k_{c, 1} C_{2} \rho_{\pi}\right)^{2}+\left(k_{d, 1} D_{2} \rho_{\pi}\right)^{2}+\lambda^{2}\right] \sigma_{\pi}^{2} \\
& \mathbb{1} \\
D_{0} & =\frac{\theta \ln (\delta)-(1-\theta)\left(k_{c, 0}+k_{c, 1} C_{0}-C_{0}\right)+k_{d, 0}}{1-k_{d, 1}} \\
& +\frac{\frac{1}{2}\left\{\left[\left(\theta-1-\frac{\theta}{\psi}\right)^{2}+\left((1-\theta) k_{c, 1} \rho_{c} C_{1}\right)^{2}+\left(k_{d, 1} D_{1} \rho_{c}\right)^{2}\right] \sigma_{c}^{2}+\left[\left(k_{d, 1} D_{3} \rho_{d}\right)^{2}+1\right] \sigma_{d}^{2}\right\}}{1-k_{d, 1}} \\
& +\frac{\frac{1}{2}\left[\left((1-\theta) k_{c, 1} C_{2} \rho_{\pi}\right)^{2}+\left(k_{d, 1} D_{2} \rho_{\pi}\right)^{2}+\lambda^{2}\right] \sigma_{\pi}^{2}}{1-k_{d, 1}} .
\end{aligned}
$$

Solving for $D_{1}$ yields (when inserting for $C_{1}$ ):

$$
\begin{aligned}
0 & =-\frac{\theta}{\psi}-(1-\theta)\left(k_{c, 1} C_{1}-C_{1}+1\right)+k_{d, 1} D_{1}-D_{1} \\
& \mathbb{} \\
D_{1} & =\frac{-\frac{1}{\psi}}{1-k_{d, 1}} .
\end{aligned}
$$

Solving for $D_{2}$ yields (when inserting for $C_{2}$ ):

$$
\begin{aligned}
0 & =-(1-\theta)\left(k_{c, 1} C_{2}-C_{2}\right)+k_{d, 1} D_{2}-D_{2}-\lambda \\
& \mathbb{} \\
D_{2} & =\frac{-\frac{\lambda}{\theta}}{1-k_{d, 1}} .
\end{aligned}
$$

Solving for $D_{3}$ yields:

$$
\begin{aligned}
0 & =k_{d, 1} D_{3}-D_{3}+1 \\
& \Uparrow \\
D_{3} & =\frac{1}{1-k_{d, 1}} .
\end{aligned}
$$




\section{References}

[1] Acker, D., and Duck, N.W. (2013a). Inflation illusion and the US dividend yield: Some further evidence. Journal of International Money and Finance 33, 235-254.

[2] Acker, D., and Duck, N.W. (2013b). Inflation illusion and the dividend yield: Evidence from the UK. European Journal of Finance 2013, 1-16.

[3] Ang, A., and Bekaert, G. (2007): Stock return predictability: Is it there? Review of Financial Studies 20, 651-707.

[4] Asness, C. (2000). Stocks versus bonds: Explaining the equity risk premium. Financial Analysts Journal, March/April 2000, 96-113.

[5] Asness, C. (2003). Fight the Fed model: The relationship between future returns and stock and bond market yields. Journal of Portfolio Management, Fall 2003, 11-24.

[6] Attanasio, O.P. and Vissing-Jorgensen, A. (2003). Stock market participation, intertemporal substitution and risk aversion. American Economic Review 93, 383-391.

[7] Attanasio, O.P. and Weber, G. (1993). Consumption growth, the interest rate and aggregation. Review of Economic Studies 60, 631-649.

[8] Bansal, R. and Yaron, A. (2004). Risks for the long run: A potential resolution of asset pricing puzzles. Journal of Finance 59, 1481-1509.

[9] Basak, S. and Yan, H. (2010). Equilibrium asset prices and investor behaviour in the presence of money illusion. Review of Economic Studies 77, 914-936.

[10] Beeler, J. and Campbell, J.Y. (2012). The long-run risks model and aggregate asset prices: An empirical assessment. Critical Finance Review 1, 141-182.

[11] Bekaert, G., and Engstrom, E. (2010). Inflation and the stock market: Understanding the "Fed model". Journal of Monetary Economics 57, 278-294.

[12] Brunnermeier, M.K., and Julliard, C. (2008). Money illusion and housing frenzies. Review of Financial Studies 21, 135-180.

[13] Burkhardt, D. and Hasseltoft, H. (2012). Understanding asset correlations. Working paper. University of Zürich.

[14] Campbell, J.Y. (1991). A variance decomposition for stock returns. Economic Journal 101, 157-179. 
[15] Campbell, J.Y., and Ammer, J. (1993). What moves the stock and bond markets? A variance decomposition for long-term asset returns. Journal of Finance 48, 3-37.

[16] Campbell, J.Y., and Shiller, R.J. (1988a). The dividend-price ratio and expectations of future dividends and discount factors. Review of Financial Studies 1, 195-228.

[17] Campbell, J.Y., and Shiller, R.J. (1988b). Stock prices, earnings and expected dividends. Journal of Finance 43, 661-676.

[18] Campbell, J.Y., and Vuolteenaho, T. (2004a). Inflation illusion and stock prices. NBER Working Paper 10263, Cambridge, MA.

[19] Campbell, J.Y., and Vuolteenaho, T. (2004b). Inflation illusion and stock prices. American Economic Review, Papers and Proceedings 94, 19-23.

[20] Chen, C.R., Lung, P.P., and Wang, F.A. (2009). Stock market mispricing: Money illusion or resale option? Journal of Financial and Quantitative Analysis 44, 11251147.

[21] Chen, L., and Zhao, X. (2009). Return decomposition. Review of Financial Studies $22,5213-5249$.

[22] Chen, X., Favilukis, J., and Ludvigson, S.C. (2013). An estimation of economic models with recursive preferences. Quantitative Economics 4, 39-83.

[23] Cochrane, J.H. (2008). The dog that did not bark. A defense of return predictability. Review of Financial Studies 21, 1533-1575.

[24] Cohen, R.B., Polk, C., and Vuolteenaho, T. (2005). Money illusion in the stock market: The Modigliani-Cohn hypothesis. Quarterly Journal of Economics 120, 639-668.

[25] Engsted, T., and Pedersen, T.Q. (2010). The dividend-price ratio does predict dividend growth: International evidence. Journal of Empirical Finance 17, 585-605.

[26] Engsted, T., Pedersen, T.Q., and Tanggaard, C. (2012a). The log-linear return approximation, bubbles, and predictability. Journal of Financial and Quantitative Analysis 47, 643-665.

[27] Engsted, T., Pedersen, T.Q., and Tanggaard, C. (2012b). Pitfalls in VAR based return decompositions: A clarification. Journal of Banking and Finance 36, 12551265. 
[28] Epstein, L. and Zin, S. (1989). Substitution, risk aversion, and the temporal behavior of consumption and asset returns: A theoretical framework. Econometrica 57, 937968.

[29] Fama, E.F., and French, K.R. (1988). Dividend yields and expected stock returns. Journal of Financial Economics 22, 3-25.

[30] Fama, E.F., and French, K.R. (1993). Common risk factors in the returns on stocks and bonds. Journal of Financial Economics 33, 3-56.

[31] Fisher, I. (1928). The Money Illusion. Adelphi, New York.

[32] Gelain, P., and Lansing, K. (2014). House prices, expectations, and time-varying fundamentals. Journal of Empirical Finance 29, 3-25.

[33] Hall, R.E. (1988). Intertemporal substitution in consumption. Journal of Political Economy 96, 339-357.

[34] Hodrick, R.J. (1992). Dividend yields and expected stock returns: Alternative procedures for inference and measurement. Review of Financial Studies 5, 357-386.

[35] Lee, B.S. (2010). Stock returns and inflation revisited: An evaluation of the inflation illusion hypothesis. Journal of Banking and Finance 34, 1257-1273.

[36] Modigliani, F., and Cohn, R.A. (1979). Inflation, rational valuation and the market. Financial Analysts Journal, March/April 1979, 24-44.

[37] Newey, W.K., and West, K.D. (1987). A simple positive semi-definite, heteroscedasticity and autocorrelation consistent covariance matrix. Econometrica 55, 703-708.

[38] Polk, C., Thompson, S., and Vuolteenaho, T. (2006). Cross-sectional forecasts of the equity premium. Journal of Financial Economics 81, 101-141.

[39] Ritter, J.R., and Warr, R.S. (2002). The decline of inflation and the bull market of 1982-1999. Journal of Financial and Quantitative Analysis 37, 29-61.

[40] Schmeling, M. and Schrimpf, A. (2011). Expected inflation, expected stock returns, and money illusion: What do we learn from survey expectations. European Economic Review 55, 702-719.

[41] Sharpe, S.A. (2002). Reexamining stock valuation and inflation: The implications of analysts' earnings forecasts. Review of Economics and Statistics 84, 632-648. 
[42] Shiller, R.J. (2000). Irrational Exuberance. Princeton University Press.

[43] Summers, L.H. (1983). The nonadjustment of nominal interest rates: A study of the Fisher effect. In: Symposium in Honor of Arthur Okun (edited by Tobin, J.), Brookings Institution, Washington DC.

[44] Wei, C. (2010). Inflation and stock prices: No illusion. Journal of Money, Credit, and Banking 42, 325-345.

[45] Weil, P. (1989). The equity premium puzzle and the risk-free rate puzzle. Journal of Monetary Economics 24, 401-421. 
Figure 1. The price-dividend ratio and the subsequent 20-year inflation rate.

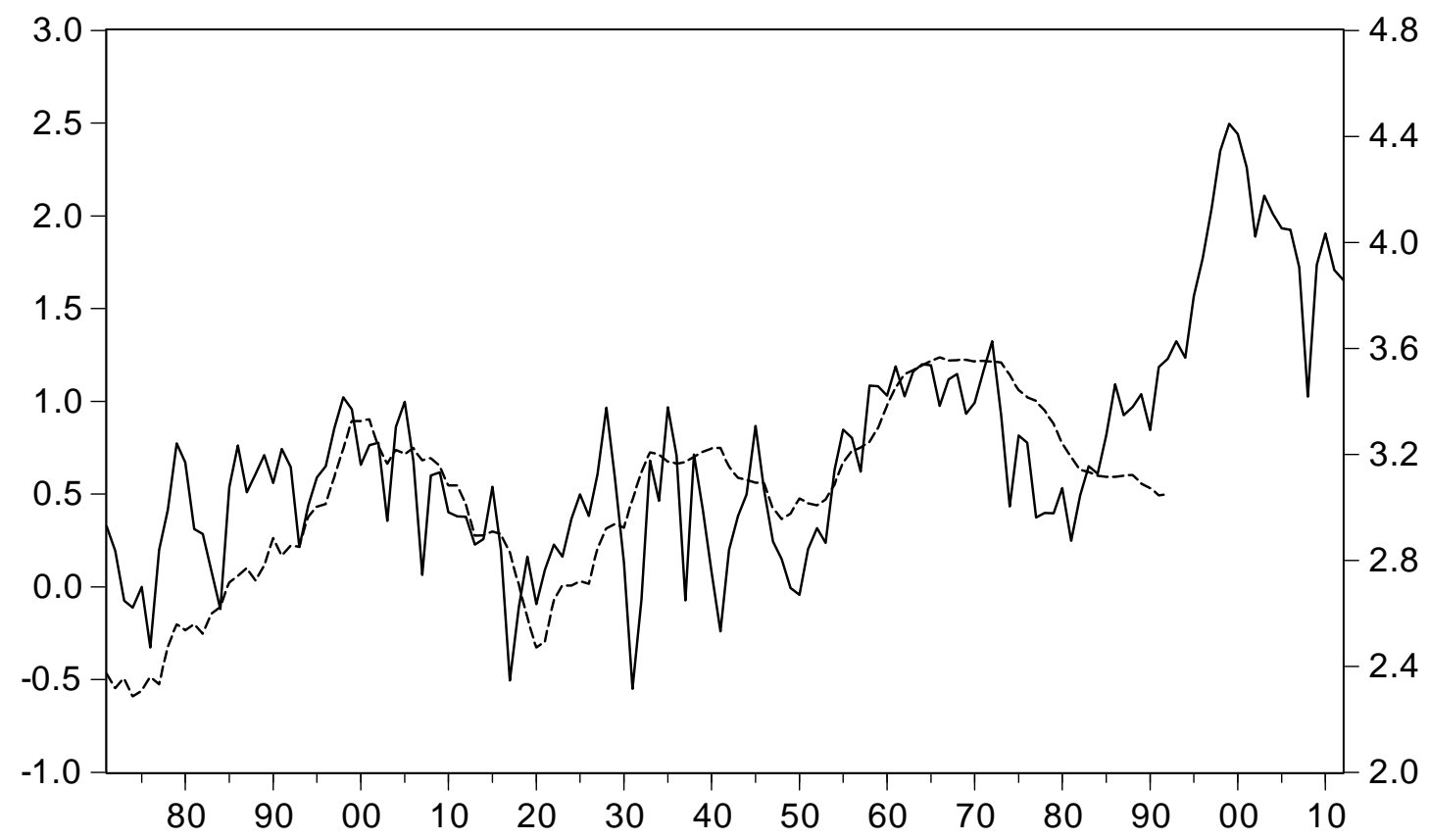

Note: The figure shows the log price-dividend ratio (solid line, right axis) and the subsequent 20-year long inflation rate (dashed line, left axis) over the period 1871-2012. For inflation the last observation is in 1992 which gives the inflation rate from 1992 to 2012. 
Figure 2. Long-horizon inflation predictability by the dividend-price ratio.
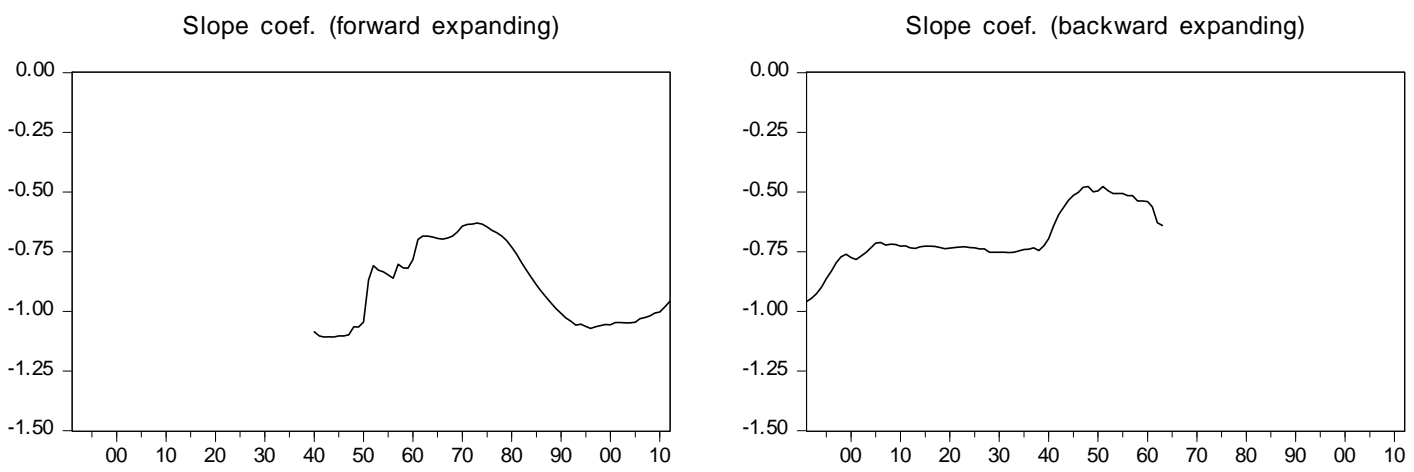

t-stat. (forward expanding)
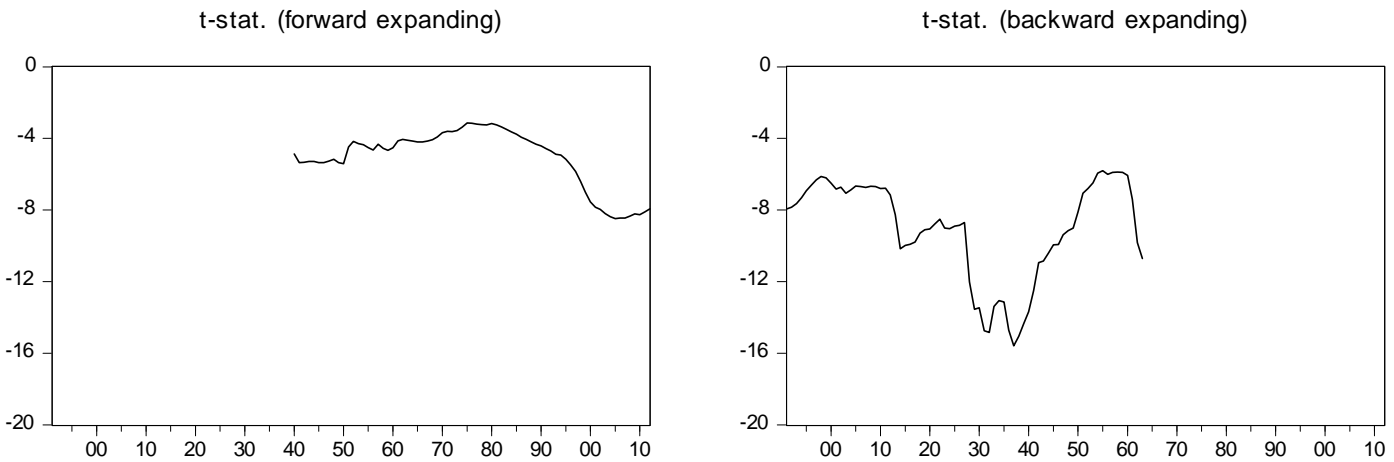

R2 (forward expanding)

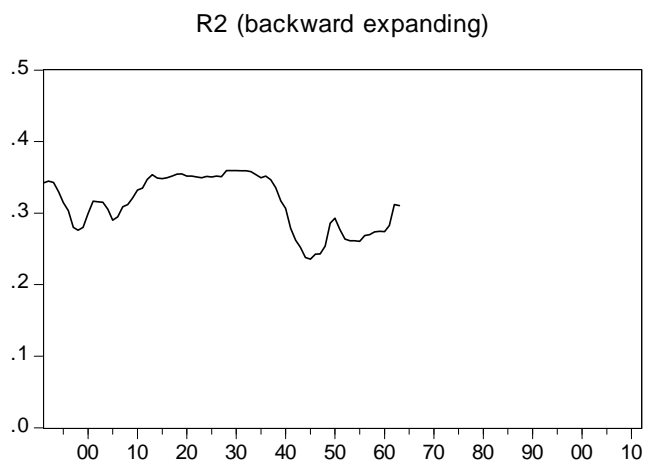

Note: The figure shows slope coefficients, corresponding t-statistics, and $\mathrm{R}^{2}$ 's when regressing 20-year log inflation on the lagged log dividend-price ratio using both a forward and backward expanding sample period. The smallest sample size is 50. In the forward (backward) expanding sample sequence the horizontal axis gives the sample end (starting) point with the sample always beginning (ending) in 1891 (2012). 
Figure 3. Inflation and real consumption growth.
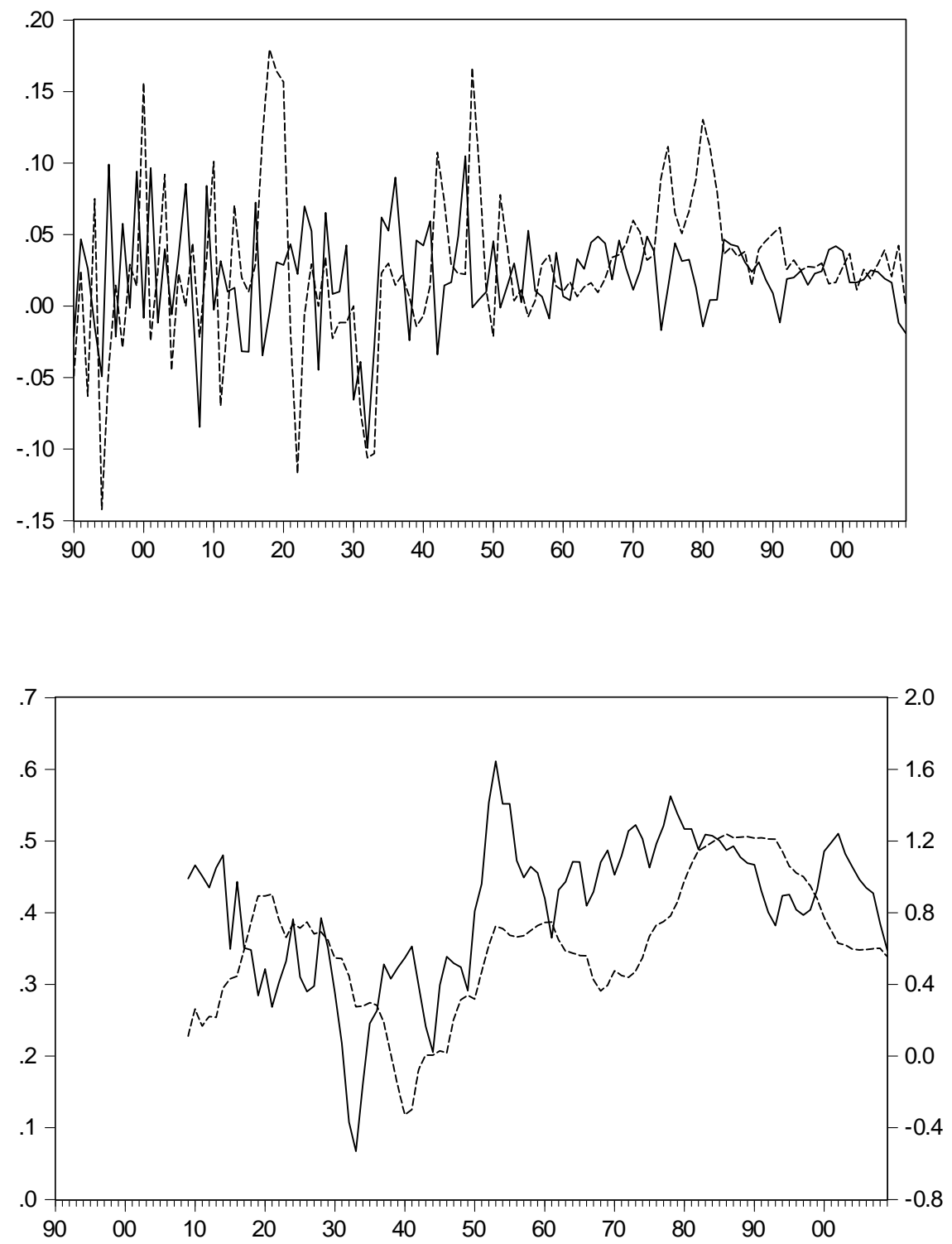

Note: The top figure shows log consumption growth (solid line) and log inflation (dashed line), both measured over one year. The bottom figure shows log consumption growth (solid line, left axis) and log inflation (dashed line, right axis), both measured over 20 years. The sample period is 1890-2009. 
Table 1. Multiperiod inflation and return predictability by the dividend-price ratio.

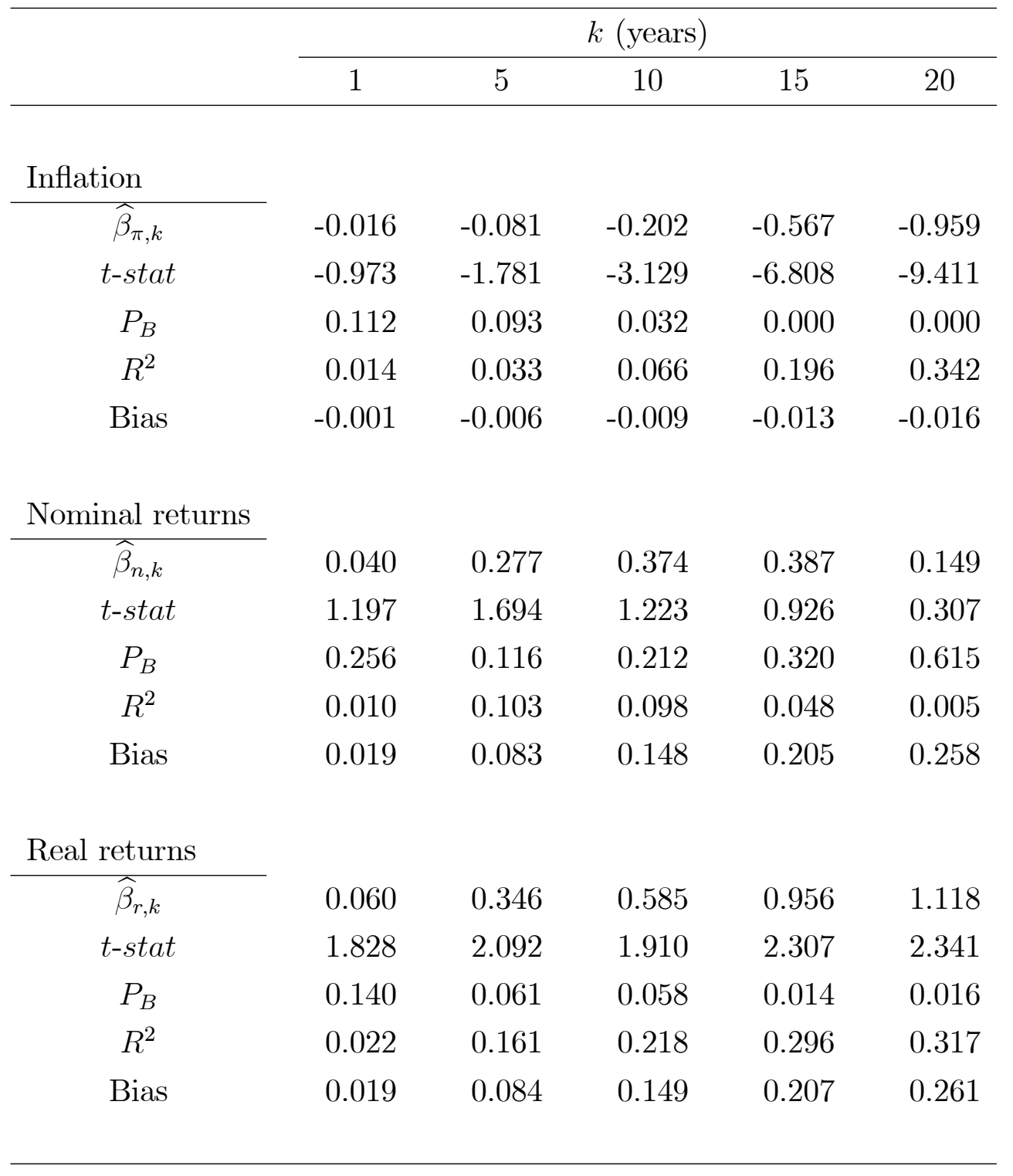

Note: The sample period is 1871-2012. k denotes the horizon in the multiperiod regression. t-statistics for $\mathrm{k}=1$ are based on Newey and West (1987) heteroskedasticity and autocorrelation robust standard errors, while for $\mathrm{k}>1$ they are based on Hodrick (1992) standard errors. $\mathrm{P}_{\mathrm{B}}$ denotes the bootstrapped p-value computed under the null hypothesis of no predictability. 
Table 2. Multiperiod inflation predictability by the dividend-price ratio and risk-premium proxies.

\begin{tabular}{cccccc}
\hline & \multicolumn{5}{c}{$k$ (years) } \\
\cline { 2 - 5 } & 1 & 5 & 10 & 15 & 20 \\
\hline$\sigma_{s} / \sigma_{b}(1881-2012)$ & & & & & \\
\cline { 1 - 2 }$\widehat{\beta}_{\pi, k}$ & 0.009 & 0.012 & -0.126 & -0.475 & -0.745 \\
& $(0.398)$ & $(0.240)$ & $(-1.824)$ & $(-4.995)$ & $(-7.366)$ \\
$\widehat{\beta}_{\sigma, k}$ & -0.002 & -0.007 & -0.000 & 0.004 & -0.005 \\
& $(-1.865)$ & $(-1.601)$ & $(-0.003)$ & $(0.320)$ & $(-0.357)$ \\
$\bar{R}^{2}$ & 0.020 & 0.024 & 0.014 & 0.136 & 0.307 \\
& & & & & \\
$\sigma_{s} / \sigma_{b}(1927-2012)$ & & & & & \\
\cline { 1 - 2 }$\widehat{\beta}_{\pi, k}$ & 0.017 & 0.036 & -0.097 & -0.461 & -0.774 \\
& $(0.834)$ & $(0.772)$ & $(-1.699)$ & $(-6.899)$ & $(-12.938)$ \\
$\widehat{\beta}_{\sigma, k}$ & -0.003 & -0.008 & -0.002 & 0.010 & 0.004 \\
& $(-2.182)$ & $(-1.424)$ & $(-0.182)$ & $(0.642)$ & $(0.272)$ \\
$\bar{R}^{2}$ & 0.047 & 0.016 & 0.009 & 0.138 & 0.338
\end{tabular}

FF3 (1927-2012)

$\begin{array}{cccccc}\widehat{\beta}_{\pi, k} & -0.000 & -0.001 & -0.041 & -0.340 & -0.655 \\ & (-0.015) & (-0.024) & (-0.720) & (-4.508) & (-7.433) \\ \widehat{\beta}_{m, k} & -0.004 & -0.106 & -0.216 & -0.689 & -0.774 \\ & (-0.104) & (-2.190) & (-3.171) & (-7.409) & (-9.151) \\ \widehat{\beta}_{s, k} & 0.002 & 0.273 & 0.406 & 0.954 & 0.723 \\ & (0.057) & (2.803) & (4.898) & (6.399) & (6.146) \\ \widehat{\beta}_{h, k} & 0.039 & 0.148 & 0.168 & 0.242 & 0.216 \\ & (1.185) & (2.053) & (3.689) & (4.386) & (6.527) \\ \bar{R}^{2} & -0.030 & 0.036 & 0.023 & 0.258 & 0.428\end{array}$

Note: $\mathrm{k}$ denotes the horizon in the multiperiod regression. t-statistics (given in parentheses) for $\mathrm{k}=1$ are based on Newey and West (1987) heteroskedasticity and autocorrelation robust standard errors, while for $\mathrm{k}>1$ they are based on Hodrick (1992) standard errors. $\sigma_{s} / \sigma_{b}$ is the volatility of stocks versus that of bonds. FF3 denotes the Fama-French three factors. 
Table 3. Inflation predictability by the dividend-price ratio under rational expectations and money illusion.

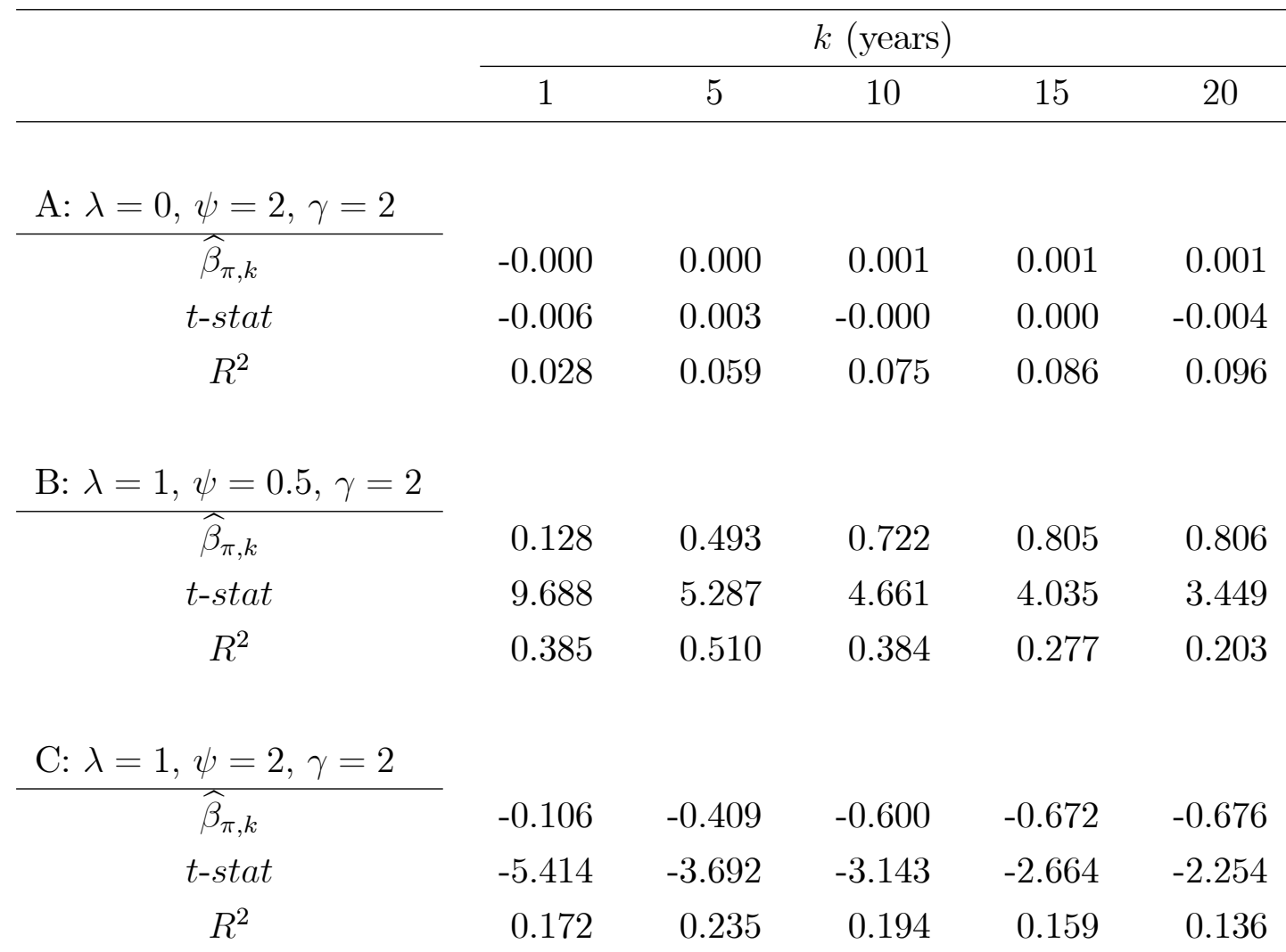

$\mathrm{D}: \lambda=1, \psi=0.5, \gamma=0$

$\begin{array}{crrrrr}\widehat{\beta}_{\pi, k} & -0.128 & -0.492 & -0.723 & -0.807 & -0.810 \\ t \text {-stat } & -9.669 & -5.291 & -4.667 & -4.046 & -3.468 \\ R^{2} & 0.385 & 0.510 & 0.384 & 0.277 & 0.203\end{array}$

Note: $\mathrm{k}$ denotes the horizon in the multiperiod regression. t-statistics for $\mathrm{k}=1$ are based on Newey and West (1987) heteroskedasticity and autocorrelation robust standard errors, while for $\mathrm{k}>1$ they are based on Hodrick (1992) standard errors. The reported numbers are averages across 10,000 simulations each of length 142 matching the length of annual dataset used in the empirical analysis. The data-generating parameters besides those given in the table are $\delta=0.95, \mu_{c}=0.020, \mu_{d}=0.013, \mu_{\pi}=0.021$, $\phi=3, \beta_{1}=\beta_{3}=0.9, \beta_{2}=0, \sigma_{c}=0.035, \sigma_{d}=0.110, \sigma_{\pi}=0.050, \sigma_{x c}=0.005, \sigma_{x \pi}=0.02$. 
Table 4. Descriptive statistics under rational expectations and money illusion.

\begin{tabular}{|c|c|c|c|}
\hline & Mean & Std.dev. & $\mathrm{AC}(1)$ \\
\hline \multicolumn{4}{|l|}{ Actual data } \\
\hline$\pi_{t}$ & 0.021 & 0.059 & 0.330 \\
\hline$\Delta d_{t}$ & 0.013 & 0.118 & 0.133 \\
\hline$\Delta c_{t}$ & 0.020 & 0.035 & -0.063 \\
\hline$p d_{t}$ & 3.206 & 0.427 & 0.873 \\
\hline \multicolumn{4}{|l|}{ Simulated data } \\
\hline$\pi_{t}$ & 0.021 & 0.065 & 0.352 \\
\hline$\Delta d_{t}$ & 0.013 & 0.114 & 0.060 \\
\hline$\Delta c_{t}$ & 0.020 & 0.037 & 0.066 \\
\hline \multicolumn{4}{|l|}{$p d_{t}$} \\
\hline $\mathrm{A}: \lambda=0, \psi=2, \gamma=2$ & 3.289 & 0.192 & 0.871 \\
\hline $\mathrm{B}: \lambda=1, \psi=0.5, \gamma=2$ & 2.225 & 0.317 & 0.871 \\
\hline $\mathrm{C}: \lambda=1, \psi=2, \gamma=2$ & 3.785 & 0.246 & 0.872 \\
\hline $\mathrm{D}: \lambda=1, \psi=0.5, \gamma=0$ & 3.649 & 0.317 & 0.872 \\
\hline
\end{tabular}

Note: For the empirical results the data source is Robert Shiller's annual data set, which covers the period 1871-2012 for dividend growth, inflation, and the price-dividend ratio. For consumption growth the sample is slightly smaller, namely 1890-2009. For the simulation results the data-generating parameters besides those given in the table can be found in Table 3. The reported numbers in the simulation study are averages across 10,000 simulations each of length 142 matching the length of annual dataset used in the empirical analysis. $\mathrm{AC}(1)$ is the first-order autocorrelation coefficient. 
Table 5. Inflation predictability by the dividend-price ratio under rational expectations and no money illusion.

\begin{tabular}{lllllll}
\hline & \multicolumn{7}{c}{$k$ (years) } \\
\cline { 2 - 6 } & 1 & 5 & 10 & 15 & 20 \\
\hline
\end{tabular}

$\mathrm{A}: \beta_{2}=0.01, \beta_{1}=0.9, \psi=2, \gamma=2$

\begin{tabular}{|c|c|c|c|c|c|}
\hline$\widehat{\beta}_{\pi, k}$ & -0.076 & -0.285 & -0.404 & -0.431 & -0.407 \\
\hline t-stat & -3.208 & -2.305 & -1.844 & -1.460 & -1.138 \\
\hline$R^{2}$ & 0.083 & 0.122 & 0.114 & 0.107 & 0.105 \\
\hline
\end{tabular}

$\mathrm{B}: \beta_{2}=0.1, \beta_{1}=0.5, \psi=2, \gamma=2$

\begin{tabular}{|c|c|c|c|c|c|}
\hline$\widehat{\beta}_{\pi, k}$ & -0.233 & -0.893 & -1.303 & -1.445 & -1.440 \\
\hline t-stat & -9.835 & -5.264 & -4.601 & -3.954 & -3.356 \\
\hline$R^{2}$ & 0.393 & 0.518 & 0.387 & 0.277 & 0.20 \\
\hline
\end{tabular}

$\mathrm{C}: \beta_{2}=-0.01, \beta_{1}=0.9, \psi=0.15, \gamma=100$

$\begin{array}{crrrrr}\widehat{\beta}_{\pi, k} & -0.051 & -0.194 & -0.174 & -0.291 & -0.272 \\ t \text {-stat } & -3.199 & -2.301 & -1.833 & -1.436 & -1.094 \\ R^{2} & 0.084 & 0.123 & 0.115 & 0.109 & 0.107\end{array}$

$\mathrm{D}: \beta_{2}=-0.1, \beta_{1}=0.5, \psi=0.15, \gamma=45$

$\begin{array}{crrrrr}\widehat{\beta}_{\pi, k} & -0.159 & -0.609 & -0.888 & -0.985 & -0.981 \\ t \text {-stat } & -9.846 & -5.263 & -4.600 & -3.951 & -3.350 \\ R^{2} & 0.393 & 0.518 & 0.387 & 0.277 & 0.201\end{array}$

Note: See the note to Table 3. The data-generating parameters besides those given in the table are $\lambda=0, \delta=0.95, \mu_{c}=0.020, \mu_{d}=0.013, \mu_{\pi}=0.021, \phi=3, \beta_{3}=0.9, \sigma_{c}=0.035$, $\sigma_{d}=0.110, \sigma_{\pi}=0.050, \sigma_{x c}=0.005, \sigma_{x \pi}=0.02$. 
Table 6. Descriptive statistics under rational expectations and no money illusion.

\begin{tabular}{|c|c|c|c|}
\hline & Mean & Std.dev. & $\mathrm{AC}(1)$ \\
\hline \multicolumn{4}{|l|}{ Actual data } \\
\hline$\pi_{t}$ & 0.021 & 0.059 & 0.330 \\
\hline$\Delta d_{t}$ & 0.013 & 0.118 & 0.133 \\
\hline$\Delta c_{t}$ & 0.020 & 0.035 & -0.063 \\
\hline$p d_{t}$ & 3.206 & 0.427 & 0.873 \\
\hline \multicolumn{4}{|l|}{ Simulated data } \\
\hline$\pi_{t}$ & 0.021 & 0.065 & 0.352 \\
\hline$\Delta d_{t}$ & 0.013 & 0.114 & 0.060 \\
\hline$\Delta c_{t}$ & 0.020 & 0.037 & 0.066 \\
\hline \multicolumn{4}{|l|}{$p d_{t}$} \\
\hline $\mathrm{A}: \beta_{2}=0.01, \beta_{1}=0.9, \psi=2, \gamma=2$ & 3.298 & 0.213 & 0.886 \\
\hline $\mathrm{B}: \beta_{2}=0.1, \beta_{1}=0.5, \psi=2, \gamma=2$ & 3.247 & 0.176 & 0.904 \\
\hline $\mathrm{C}: \beta_{2}=-0.01, \beta_{1}=0.9, \psi=0.15, \gamma=100$ & 3.031 & 0.312 & 0.886 \\
\hline $\mathrm{D}: \beta_{2}=-0.1, \beta_{1}=0.5, \psi=0.15, \gamma=45$ & 3.292 & 0.258 & 0.904 \\
\hline
\end{tabular}

Note: See the note to Table 4. For the simulation results the data-generating parameters besides those given in the table can be found in Table 5. For consumption and dividend growth there are only very small differences in the autocorrelation coefficient across the four scenarios and compared to those based on money illusion (Table 4). For ease of exposition the reported simulation results for consumption and dividend growth are thus reproduced from Table 4. 
Table 7. Inflation predictability by the dividend-price ratio under adaptive expectations and money illusion.

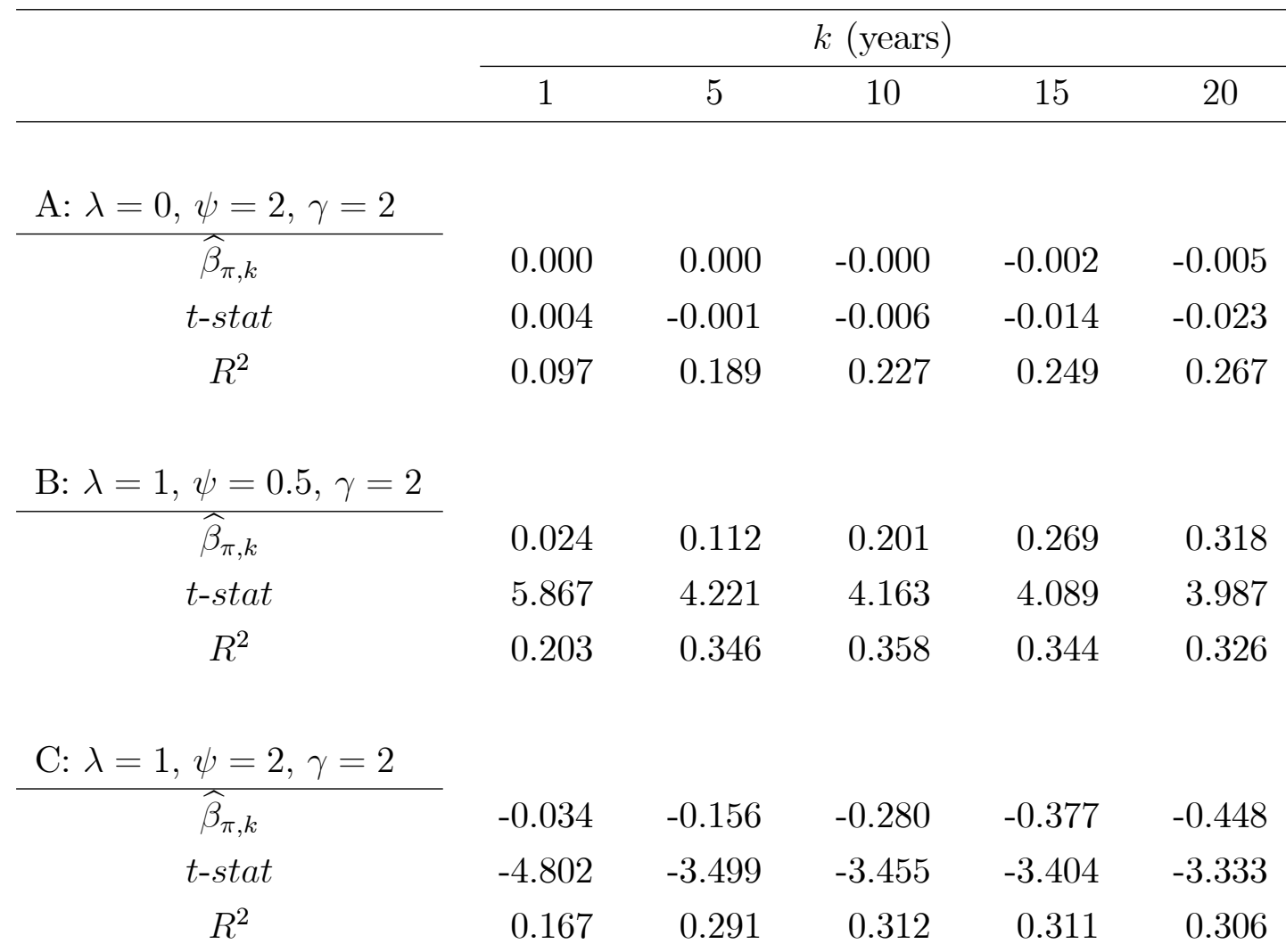

$\mathrm{D}: \lambda=1, \psi=0.7, \gamma=0$

$\begin{array}{crrrrr}\widehat{\beta}_{\pi, k} & -0.033 & -0.151 & -0.272 & -0.366 & -0.436 \\ t \text {-stat } & -4.355 & -3.186 & -3.145 & -3.099 & -3.037 \\ R^{2} & 0.155 & 0.271 & 0.296 & 0.299 & 0.298\end{array}$

Note: See the note to Table 3. The data-generating parameters besides those given in the table are $\delta=0.95, \sigma_{c}=0.035, \sigma_{d}=0.11, \sigma_{\pi}=0.05, \rho_{c}=0.02, \rho_{d}=0.03, \rho_{\pi}=0.15$. For each simulation the initial values of expected consumption growth, dividend growth, and inflation are drawn randomly from normal distributions with means and standard deviations matching those from empirical data. 
Table 8. Descriptive statistics under adaptive expectations and money illusion.

\begin{tabular}{|c|c|c|c|}
\hline & Mean & Std.dev. & $\mathrm{AC}(1)$ \\
\hline \multicolumn{4}{|l|}{ Actual data } \\
\hline$\pi_{t}$ & 0.021 & 0.059 & 0.330 \\
\hline$\Delta d_{t}$ & 0.013 & 0.118 & 0.133 \\
\hline$\Delta c_{t}$ & 0.020 & 0.035 & -0.063 \\
\hline$p d_{t}$ & 3.206 & 0.427 & 0.873 \\
\hline \multicolumn{4}{|l|}{ Simulated data } \\
\hline$\pi_{t}$ & 0.020 & 0.058 & 0.317 \\
\hline$\Delta d_{t}$ & 0.013 & 0.109 & 0.012 \\
\hline$\Delta c_{t}$ & 0.020 & 0.035 & 0.003 \\
\hline \multicolumn{4}{|l|}{$p d_{t}$} \\
\hline $\mathrm{A}: \lambda=0, \psi=2, \gamma=2$ & 3.184 & 0.373 & 0.962 \\
\hline $\mathrm{B}: \lambda=1, \psi=0.5, \gamma=2$ & 2.495 & 0.935 & 0.962 \\
\hline $\mathrm{C}: \lambda=1, \psi=2, \gamma=2$ & 3.888 & 0.563 & 0.962 \\
\hline $\mathrm{D}: \lambda=1, \psi=0.7, \gamma=0$ & 3.251 & 0.530 & 0.962 \\
\hline
\end{tabular}

Note: See the note to Table 4 . For the simulation results the data-generating parameters besides those given in the table can be found in Table 7 . 
Table 9. The Campbell-Voulteenaho approach.

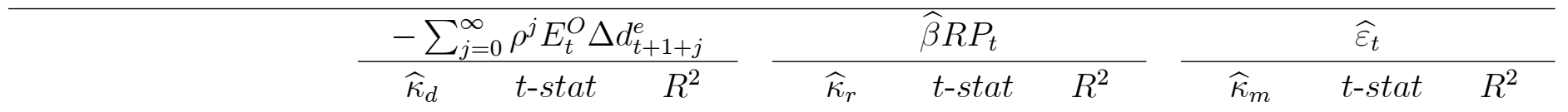

Expected inflation:

Smoothed past inflation, $\rho_{\pi}=0.5$

$\begin{array}{rrrrrrrrrr}1881-2012 & -1.159 & -2.415 & 0.076 & -1.044 & -3.260 & 0.117 & 2.494 & 3.379 & 0.142 \\ 1881-1945 & -0.248 & -0.652 & 0.005 & 0.049 & 1.197 & 0.018 & 1.364 & 2.620 & 0.191 \\ 1946-2012 & -0.825 & -0.665 & 0.011 & -0.088 & -0.031 & 0.000 & 9.866 & 5.850 & 0.421 \\ 1927-2002 & 0.982 & 0.684 & 0.009 & -6.693 & -3.120 & 0.164 & 5.813 & 2.929 & 0.221\end{array}$

Smoothed past inflation, $\rho_{\pi}=0.1$

$\begin{array}{rrrrrrrrrr}1881-2012 & -6.139 & -16.254 & 0.729 & -2.638 & -5.509 & 0.373 & 5.498 & 4.242 & 0.228 \\ 1881-1945 & -3.932 & -5.642 & 0.315 & 0.255 & 1.400 & 0.057 & 6.254 & 8.138 & 0.691 \\ 1946-2012 & 13.675 & 7.159 & 0.494 & -7.844 & -1.524 & 0.048 & 4.454 & 1.331 & 0.035 \\ 1927-2002 & 7.018 & 4.586 & 0.368 & -14.684 & -4.882 & 0.553 & 2.615 & 0.969 & 0.026\end{array}$

Smoothed past inflation, $\rho_{\pi}=0.9$

\begin{tabular}{llllllllll}
\hline $1881-2012$ & -0.513 & -1.494 & 0.025 & -0.562 & -2.772 & 0.059 & 1.331 & 2.245 & 0.067 \\
$1881-1945$ & -0.117 & -0.409 & 0.002 & 0.017 & 0.556 & 0.004 & 0.767 & 1.765 & 0.113 \\
$1946-2012$ & -0.433 & -0.429 & 0.005 & -0.247 & -0.107 & 0.000 & 6.340 & 4.003 & 0.284 \\
$1927-2002$ & 0.565 & 0.529 & 0.004 & -4.508 & -2.743 & 0.103 & 3.393 & 2.431 & 0.146
\end{tabular}

Long-term bond yield

$\begin{array}{rrrrrrrrrr}1881-2012 & 2.774 & 1.684 & 0.065 & -2.995 & -3.803 & 0.305 & -3.028 & -2.821 & 0.075 \\ 1881-1945 & 22.937 & 5.793 & 0.429 & 1.572 & 1.962 & 0.108 & -14.156 & -2.213 & 0.251 \\ 1946-2012 & 14.612 & 19.746 & 0.940 & -9.045 & -1.974 & 0.252 & -3.631 & -2.237 & 0.161 \\ 1927-2002 & 13.215 & 7.062 & 0.729 & -15.251 & -3.332 & 0.435 & -1.456 & -0.700 & 0.010\end{array}$

Note: t-statistics are based on Newey and West (1987) heteroskedasticity and autocorrelation robust standard errors. 
2015-54: $\quad$ Peter Christoffersen, Mathieu Fournier, Kris Jacobs and Mehdi Karoui: Option-Based Estimation of the Price of Co-Skewness and Co-Kurtosis Risk

2015-55 Kadir G. Babaglou, Peter Christoffersen, Steven L. Heston and Kris Jacobs: Option Valuation with Volatility Components, Fat Tails, and Nonlinear Pricing Kernels

2015-56: $\quad$ Andreas Basse-O'Connor, Raphaël Lachièze-Rey and Mark Podolskij: Limit theorems for stationary increments Lévy driven moving averages

2015-57: $\quad$ Andreas Basse-O'Connor and Mark Podolskij: On critical cases in limit theory for stationary increments Lévy driven moving averages

2015-58: $\quad$ Yunus Emre Ergemen, Niels Haldrup and Carlos Vladimir Rodríguez-Caballero: Common long-range dependence in a panel of hourly Nord Pool electricity prices and loads

2015-59: $\quad$ Niels Haldrup and J. Eduardo Vera-Valdés: Long Memory, Fractional Integration, and Cross-Sectional Aggregation

2015-60: Mark Podolskij, Bezirgen Veliyev and Nakahiro Yoshida: Edgeworth expansion for the pre-averaging estimator

2016-01: Matei Demetrescum, Christoph Hanck and Robinson Kruse: Fixed-b Inference in the Presence of Time-Varying Volatility

2016-02: $\quad$ Yunus Emre Ergemen: System Estimation of Panel Data Models under LongRange Dependence

2016-03: Bent Jesper Christensen and Rasmus T. Varneskov: Dynamic Global Currency Hedging

2016-04: $\quad$ Markku Lanne and Jani Luoto: Data-Driven Inference on Sign Restrictions in Bayesian Structural Vector Autoregression

2016-05: $\quad$ Yunus Emre Ergemen: Generalized Efficient Inference on Factor Models with Long-Range Dependence

2016-06: $\quad$ Girum D. Abate and Luc Anselin: House price fluctuations and the business cycle dynamics

2016-07: $\quad$ Gustavo Fruet Dias, Cristina M. Scherrer and Fotis Papailias: Volatility Discovery

2016-08 N. Haldrup, O. Knapik and T. Proietti: A generalized exponential time series regression model for electricity prices

2016-09: Ole E. Barndorff-Nielsen: Assessing Gamma kernels and BSS/LSS processes

2016-10: $\quad$ Tim Bollerslev, Andrew J. Patton and Rogier Quaedvlieg: Modeling and Forecasting (Un)Reliable Realized Covariances for More Reliable Financial Decisions

2016-11: Tom Engsted and Thomas Q. Pedersen: The predictive power of dividend yields for future inflaation: Money illusion or rational causes? 